\title{
Further Investigations of NIST Water Sphere Discrepancies
}

\author{
B. L. Broadhead \\ C. M. Hopper \\ S. C. Frankle \\ J. F. Briesmeister \\ R. C. Little \\ J. J. Wagschal
}

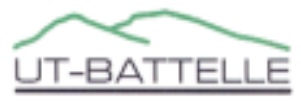


This report has been reproduced from the best available copy.

Reports are available to the public from the following source.

National Technical Information Service

5285 Port Royal Road

Springfield, VA 22161

Telephone 703-605-6000 (1-800-553-6847)

TDD 703-487-4639

Fax 703-605-6900

E-mail orders@ntis.fedworld.gov

Web site http://www.ntis.gov/ordering.htm

Reports are available to U.S. Department of Energy (DOE) employees, DOE contractors, Energy

Technology Data Exchange (ETDE) representatives, and International Nuclear Information

System (INIS) representatives from the following source.

Office of Scientific and Technical Information

P.O. Box 62

Oak Ridge, TN 37831

Telephone 423-576-8401

Fax 423-576-5728

E-mail reports@adonis.osti.gov

Web site http://www.osti.gov/products/sources.html

Reports produced after January 1, 1996, are generally available via the DOE Information Bridge.

Web site http://www.doe.gov/bridge

This report was prepared as an account of work sponsored by an agency of the United States government. Neither the United States government nor any agency thereof, nor any of their employees, makes any warranty, express or implied, or assumes any legal liability or responsibility for the accuracy, completeness, or usefulness of any information, apparatus, product, or process disclosed, or represents that its use would not infringe privately owned rights. Reference herein to any specific commercial product, process, or service by trade name, trademark, manufacturer, or otherwise, does not necessarily constitute or imply its endorsement, recommendation, or favoring by the United States government or any agency thereof. The views and opinions of authors expressed herein do not necessarily state or reflect those of the United States government or any agency thereof. 
ORNL/TM-2000/173

Computational Physics and Engineering Division (10)

\section{Further Investigations of NIST Water Sphere Discrepancies}

B. L. Broadhead, C. M. Hopper

Oak Ridge National Laboratory

P.O. Box 2008

Oak Ridge, TN 37831-6370

S. C. Frankle, J. F. Briesmeister, R. C. Little

Los Alamos National Laboratory

Group X-5 MS-F663

Los Alamos, NM 87545

J. J. Wagschal

Racah Institute of Physics

The Hebrew University of Jerusalem

91904, Jerusalem

ISRAEL

Date Published: October 2000

Prepared by

OAK RIDGE NATIONAL LABORATORY

Oak Ridge, Tennessee 37831-6285

managed by

UT-BATTELLE, LLC.

for the

U.S. DEPARTMENT OF ENERGY

under contract DE-AC05-00OR22725 



\section{CONTENTS}

$\underline{\text { Page }}$

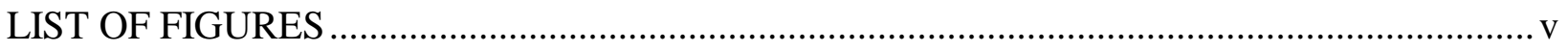

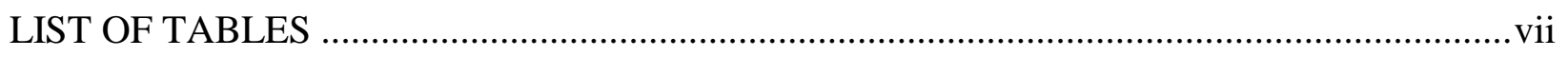

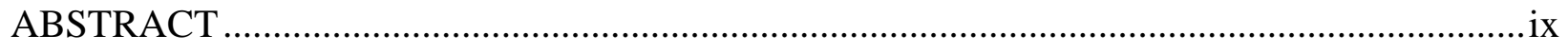

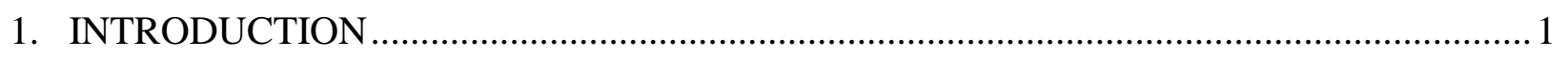

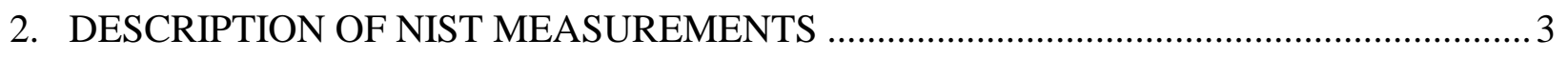

3. DESCRIPTION OF THE MONTE CARLO CALCULATIONS .....................................

3.1. Comparison to Previous ENDF/B-V Results .......................................................... 7

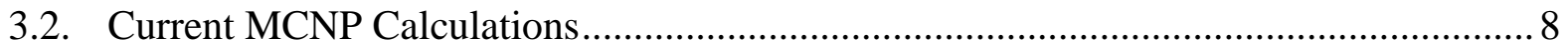

4. APPLICATION OF GLLSM TOOLS TO NIST WATER SPHERES ............................. 13

4.1. Joint Consistency Analysis ............................................................................. 17

4.2. Qualitative Comparison of GLLSM-Predicted Data Changes With

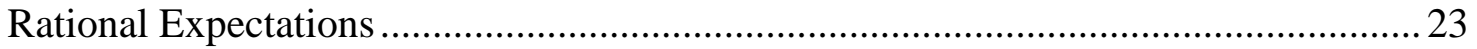

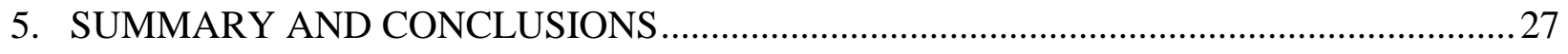

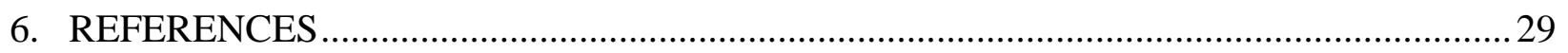




\section{LIST OF FIGURES}

$\underline{\text { Figure }}$

Page

1. NIST experimental geometry for the 5.08-cm (2-in.) sphere. ....................................... 4

2. Neutron flux spectra for the 5.08-cm (2-in.)-sphere experiments

at the response foil locations.

3. Total absorption cross section for cadmium from ENDF/B-V.................................. 7

4. The relative deviations of measured (E) from calculated (C) average fission cross sections outside NIST water spheres driven by a central ${ }^{252} \mathrm{Cf}$ spontaneous fission neutron source and the respective relative uncertainties.

5. Individual chi square values for various measured and calculated average fission cross sections measured outside NIST water spheres driven by a central ${ }^{252} \mathrm{Cf}$ spontaneous fission neutron source.

6. The relative deviations of calculated (C) and adjusted (A) from measured (E) average fission cross sections outside NIST water spheres driven by a ${ }^{252} \mathrm{Cf}$ spontaneous fission neutron source and the respective relative uncertainties.

7. The relative deviations of calculated (C) and adjusted (A) from measured (E) average fission cross sections outside NIST water spheres driven by a central ${ }^{252} \mathrm{Cf}$ spontaneous fission neutron source and the respective relative uncertainties. All measurements are correlated with each other.

8. The relative deviations of calculated (C) and adjusted (A) from measured (E) average fission cross sections outside NIST water spheres driven by a central ${ }^{252} \mathrm{Cf}$ spontaneousfission neutrons source and the respective relative uncertainties.

(Only four measurements actively participated in the adjustment.).

9. The relative deviations of calculated (C) and adjusted (A) from measured (E) average fission cross sections outside NIST water spheres driven by a central ${ }^{252} \mathrm{Cf}$ spontaneousfission neutron source and the respective relative uncertainties.

(Only four measurements actively participated in the adjustment. All measurements are correlated.). 


\section{LIST OF FIGURES (continued)}

$\underline{\text { Figure }}$

$\underline{\text { Page }}$

10. The relative deviations of calculated $(\mathrm{C})$ and adjusted (A) from measured (E) average fission cross sections outside NIST water spheres driven by a central ${ }^{252} \mathrm{Cf}$ spontaneous fission neutron source and the respective relative uncertainties. (Only one measurement actively participated in the adjustment. All measurements are correlated.).

11. The relative deviations of calculated $(\mathrm{C})$ and adjusted $(\mathrm{A})$ from measured $(\mathrm{E})$ average fission cross sections outside NIST water spheres driven by ${ }^{252} \mathrm{Cf}$ spontaneous fission neutrons at their center and the respective relative uncertainties. (All measurements of the intermediate sphere did not actively participate in the adjustment. All measurements are correlated.)

12. The relative deviations of calculated (C) and adjusted (A) from measured (E) average fission cross sections outside NIST water spheres driven by a central ${ }^{252} \mathrm{Cf}$ spontaneous fission neutron source and the respective relative uncertainties. (All measurements of the intermediate sphere did not actively participate in the adjustment.

All measurements are correlated.)

13. Comparison of NIST-supplied, LANL continuous energy, and adjusted fission spectra for ${ }^{252} \mathrm{Cf}$ 


\section{LIST OF TABLES}

Table

$\underline{\text { Page }}$

1. Data used for the response fission rate calculations in MCNP ........................................ 6

2. Comparison of original (ENDF/B-V) and current (ENDF/B-VI) transport calculations with experiment.

3. Comparison of MCNP calculations with various ${ }^{235} \mathrm{U}$ fission cross sections to NIST experimental measurements

4. Comparison of MCNP calculations with various ${ }^{238} \mathrm{U}$ response fission cross sections to NIST experimental measurements .

5. Comparison of MCNP calculations with various ${ }^{237} \mathrm{~Np}$ fission cross sections to NIST experimental measurements ....

6. Comparison of MCNP calculations with various ${ }^{239} \mathrm{Pu}$ response fission cross sections to NIST experimental measurements

7. Various measured and calculated average fission cross sections outside NIST water spheres driven by a central ${ }^{252} \mathrm{Cf}$ spontaneous fission neutron source 


\section{ABSTRACT}

Measurements have been performed on a family of water spheres at the National Institute of Standards and Technology (NIST) facilities. These measurements are important for criticality safety studies in that, frequently, difficulties have arisen in predicting the reactivity of individually subcritical components assembled in a critical array. It has been postulated that errors in the neutron leakage from individual elements in the array could be responsible for these problems. In these NIST measurements, an accurate determination of the leakage from a fission spectrum, modified by water scattering, is available.

Previously, results for 3-, 4-, and 5-in. diam. water-filled spheres, both with and without cadmium covers over the fission chambers, were presented for four fissionable materials: ${ }^{235} \mathrm{U},{ }^{238} \mathrm{U}$,

${ }^{237} \mathrm{~Np}$, and ${ }^{239} \mathrm{Pu}$. Results were also given for "dry" systems, in which the water spheres were drained of water, with the results corresponding to essentially measurements of unmoderated ${ }^{252} \mathrm{Cf}$ spontaneousfission neutrons. The calculated-to-experimental $(\mathrm{C} / \mathrm{E})$ values ranged from 0.94 to 1.01 for the dry systems and 0.93 to 1.05 for the wet systems, with experimental uncertainties ranging from 1.5 to $1.9 \%$. These results indicated discrepancies that were clearly outside of the experimental uncertainties, and further investigation was suggested.

This work updates the previous calculations with a comparison of the predicted $\mathrm{C} / \mathrm{E}$ values with ENDF/B-V and ENDF/B-VI transport cross sections. Variations in the predicted C/E values that arise from the use of ENDF/B-V, ENDF/B-VI, ENDL92, and LLLDOS for the response fission cross sections are also tabulated. The use of both a 45-group NIST fission spectrum and a continuous-energy fission spectrum for ${ }^{252} \mathrm{Cf}$ are evaluated. 
The use of the generalized-linear-least-squares (GLLSM) procedures to investigate the reported discrepancies in the water sphere results for ${ }^{235} \mathrm{U},{ }^{238} \mathrm{U},{ }^{239} \mathrm{Pu}$, and ${ }^{237} \mathrm{~Np}$ is reported herein. These studies should be a valuable exercise to demonstrate the utility of the GLLS methodology and to attempt to understand the discrepancies seen. 


\section{INTRODUCTION}

Over the past 10 years, various groups from the National Institute of Standards and Technology (NIST), Los Alamos National Laboratory (LANL), and Oak Ridge National Laboratory (ORNL) have analyzed the results of measurements performed on a family of water spheres at the NIST facilities. $1-3$ These measurements are important for criticality safety studies in that, frequently, difficulties have arisen in predicting the reactivity of individually subcritical components assembled in a critical array. It has been postulated that errors in the neutron leakage from individual elements in an array could be responsible for these difficulties. An accurate determination of the leakage from a fission spectrum, modified by water scattering, is available in the NIST measurements.

The NIST experiments are unique in their simplicity, flexibility, and cost-effectiveness. They are designed to be essentially one-dimensional (1-D); however, more accurate results currently require multidimensional techniques. They are quite flexible in that only the shell needs to be replaced in order to perform experiments on an entirely new configuration. Experiments can be easily envisioned to address concerns in various materials [i.e., iron (partially completed), aluminum, silicon dioxide, etc.]. These experiments are very cost-effective, because very little fissile material has to be stored and handled. The primary items necessary for additional experiments are the existing source and detectors, along with shells of the particular material of interest.

The capabilities of the NIST facility mesh very nicely with some of the potential uses of the generalized-linear-least-squares methodology (GLLSM $)^{4}$ that is currently being developed as a part of the DOE Nuclear Criticality Safety Program. For example, these water-sphere measurements can be considered as a variable thickness "filter" in which the energies of interest for the fission cross sections for various fissile materials can be tested, as well as various degrees of moderation due to water scattering. Similar tests could also be performed for other moderators of interest. The utility of these experiments in the GLLSM procedure is that they give information of value to criticality safety 
applications that would otherwise be gained by performing critical experiments. This situation is analogous to the use of resonance integral and thermal cross-section values to aid in the normalization of measured cross-section shapes by cross-section evaluators.

Previously $\frac{3}{3}$ results for 3-, 4-, and 5-in. diam. water-filled spheres, both with and without cadmium-covers over the fission chambers, were presented for four fissionable materials: ${ }^{235} \mathrm{U},{ }^{238} \mathrm{U}$, ${ }^{237} \mathrm{~Np}$, and ${ }^{239} \mathrm{Pu}$. Results ${ }^{2}$ were also given for "dry" systems, in which the water spheres were drained, corresponding to measurements of essentially unmoderated ${ }^{252} \mathrm{Cf}$ spontaneous-fission neutrons. The calculated-to-experimental $(\mathrm{C} / \mathrm{E})$ values ranged from 0.94 to 1.01 for the dry systems and 0.93 to 1.05 for the wet systems, with experimental uncertainties ranging from 1.5 to $1.9 \%$. These results indicated discrepancies that were clearly outside of the experimental uncertainties, suggesting the need for further investigation.

As was indicated earlier, the experiments consist of a neutron source (i.e., ${ }^{252} \mathrm{Cf}$ spontaneous fission); a medium through which the neutrons transport (i.e., water); and a response measurement (i.e., various fission foils). For an unequivocal analysis of the experiments, parameters relevant to each of these constituents should be varied independently. Thus, the neutron source, transport cross sections, and fission cross sections were separately varied in this study to determine their effects on the overall results. This work updates the previous calculations with a comparison of the predicted C/E values with $\mathrm{ENDF} / \mathrm{B}-\sqrt{5}$ and ENDF/B-VI $\mathrm{V}^{6}$ transport cross sections. Variations in the predicted C/E values that arise from the use of ENDF/B-V, ENDF/B-VI, ENDL92 (ref. 7), and LLLDO\$ ${ }^{8}$ for the response fission cross sections are also tabulated. Finally, the use of both a 45-group NIST fission spectrun? 9 and a continuousenergy fission spectrum ${ }^{10}$ for ${ }^{252} \mathrm{Cf}$ are evaluated.

The use of the GLLSM procedures to investigate the reported discrepancies in the water-sphere results for ${ }^{235} \mathrm{U},{ }^{238} \mathrm{U},{ }^{239} \mathrm{Pu}$, and ${ }^{237} \mathrm{~Np}$ is reported herein. These studies are expected to be valuable for demonstrating the utility of the GLLSM procedures and understanding the reported discrepancies. 


\section{DESCRIPTION OF NIST MEASUREMENTS}

A very detailed set of experimental measurements was performed at the NIST facilities. A thinencapsulated ${ }^{252} \mathrm{Cf}$-neutron source was suspended via a thin-walled stainless steel tube to the center of a spherical shell of stainless steel. A pair of double-fission chambers was positioned symmetrically on opposite sides of the spherical shell. Each double-fission chamber contained two foils positioned at either side of the center of the chamber, generally within $0.03 \mathrm{~cm}$ of each other. Figure 1 shows an illustration of the experimental geometry. Measurements were performed with the stainless steel tube and spherical container either dry or filled with pure water. Measurements were performed with bare and cadmium- covered fission chambers. Three sets of measurements, utilizing different sized containers, were performed for foils of ${ }^{235} \mathrm{U},{ }^{238} \mathrm{U},{ }^{237} \mathrm{~Np}$, and ${ }^{239} \mathrm{Pu}$. The stainless steel spherical-shell containers for the three sets of measurements had radii of 3.81, 5.08, and $6.35 \mathrm{~cm}(1.5-, 2.0-$, and 2.5-in. radii), with corresponding average foil positions of $7.62,7.62$ and $9.525 \mathrm{~cm}$. Therefore, for each foil location and foil type, four measurements were made; no water or cadmium (bare), no water with cadmium (Cd), water and no cadmium $\left(\mathrm{H}_{2} \mathrm{O}\right)$, and water with cadmium $\left(\mathrm{H}_{2} \mathrm{O}+\mathrm{Cd}\right)$. The measurement results have been previously reported $;$ however, the dry results for the largest sphere are currently not available. The latter measurements were performed, but only as a check of previous measurements, since they were not expected to deviate from those of the smaller spheres. 


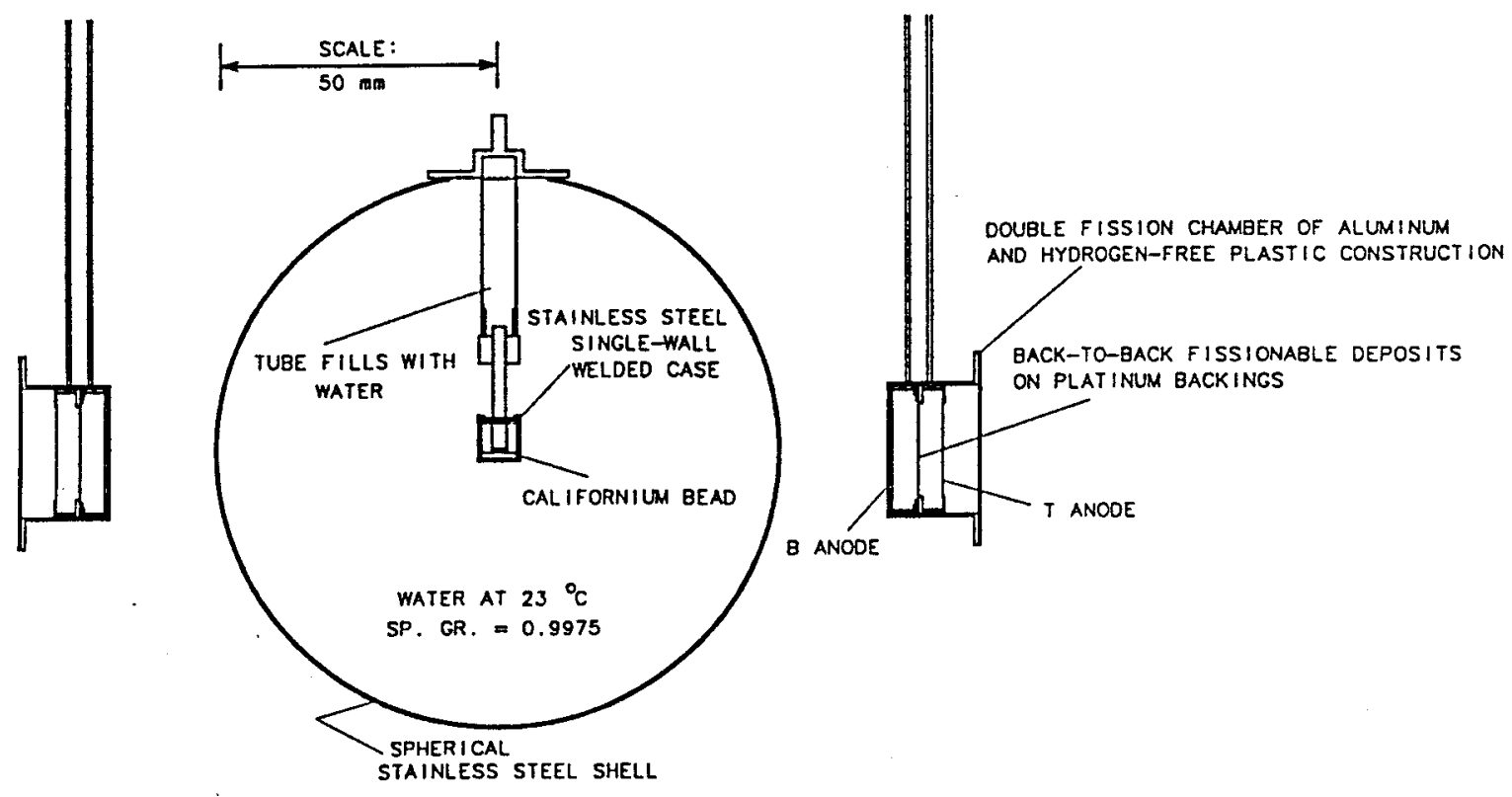

Fig. 1. NIST experimental geometry for the 5.08-cm (2-in.) sphere. 


\section{DESCRIPTION OF THE MONTE CARLO CALCULATIONS}

Previously, multidimensional calculations were performed ${ }^{3}$ by both the LANL and ORNL staff using ENDF/B-V cross sections. Those calculations indicated that, while simple one-dimensional models gave consistent results between the organizations, they significantly underpredicted the measurements by up to $30 \%$. As a result, a multidimensional $\mathrm{MCNP}^{11}$ model with detailed geometry was constructed by LANL staff for further studies. Previous studies showed that the contributions from neutrons scattered by the laboratory floor and other structures were negligible, and thus these structures were not included in the MCNP model ${ }^{2,3}$ Various variance-reduction methods were employed for the different experimental geometries. To compare with the published experimental fission rates, the contributions from the inner left and right foil positions (see Fig. 1) were summed and the contributions from the outer left and right foil positions were summed. These two sums were then averaged and multiplied by $4 \pi r^{2}$, where $r$ is the average radius of the foil positions in $\mathrm{cm}$. F2 tallies for the flux through a surface at each foil location were multiplied by the appropriate fission cross section as a function of neutron energy using the FM tally option in MCNP.

For the current calculations, the ENDF60 neutron-data library based on ENDF/B-VI was used for most of the material specifications for the transport calculations. Exceptions were the use of the ENDL92 data for platinum, and the ENDF/B-V data of ENDF5U for cadmium. Table 1 lists the specific data libraries used in the fission-rate calculations for each isotope of interest. Figure 2 shows the neutron-flux spectrum at the foil locations for the bare sphere (bare), bare sphere with cadmium-covered fission chambers $(\mathrm{Cd})$, water-moderated sphere $\left(\mathrm{H}_{2} \mathrm{O}\right)$, and water-moderated sphere with cadmiumcovered chambers $\left(\mathrm{H}_{2} \mathrm{O}+\mathrm{Cd}\right)$ for the 2-in. radius sphere experiments. In Fig. 2, the curves for the bare and cadmium-covered fission chambers overlap. The total absorption cross section for cadmium is shown in Fig. 3. 
Table 1. Data used for the response fission rate calculations in MCNP

\begin{tabular}{ccccc}
\hline & $\begin{array}{c}\text { ENDF/B-VI } \\
\text { ENDF/B-V } \\
\text { Release 2 }\end{array}$ & $\begin{array}{c}\text { Release 2 } \\
\text { (ENDF60) }\end{array}$ & ENDL92 & $\begin{array}{c}\text { LLLDOS } \\
\text { (ACTL) }\end{array}$ \\
\hline${ }^{235} \mathrm{U}$ & $92235.50 \mathrm{c}$ & $92235.60 \mathrm{c}$ & $92235.42 \mathrm{c}$ & $92235.30 \mathrm{y}$ \\
${ }^{238} \mathrm{U}$ & $92238.50 \mathrm{c}$ & $92238.60 \mathrm{c}$ & $92238.42 \mathrm{c}$ & $92238.30 \mathrm{y}$ \\
${ }^{237} \mathrm{~Np}$ & $93237.55 \mathrm{c}^{a}$ & $93237.60 \mathrm{c}$ & $93237.42 \mathrm{c}$ & $93237.30 \mathrm{y}$ \\
${ }^{239} \mathrm{Pu}$ & $94239.55 \mathrm{c}$ & $94239.60 \mathrm{c}$ & $94239.42 \mathrm{c}$ & $94239.30 \mathrm{y}$ \\
\hline
\end{tabular}

${ }^{a}$ LANL evaluation, not ENDF/B-V.

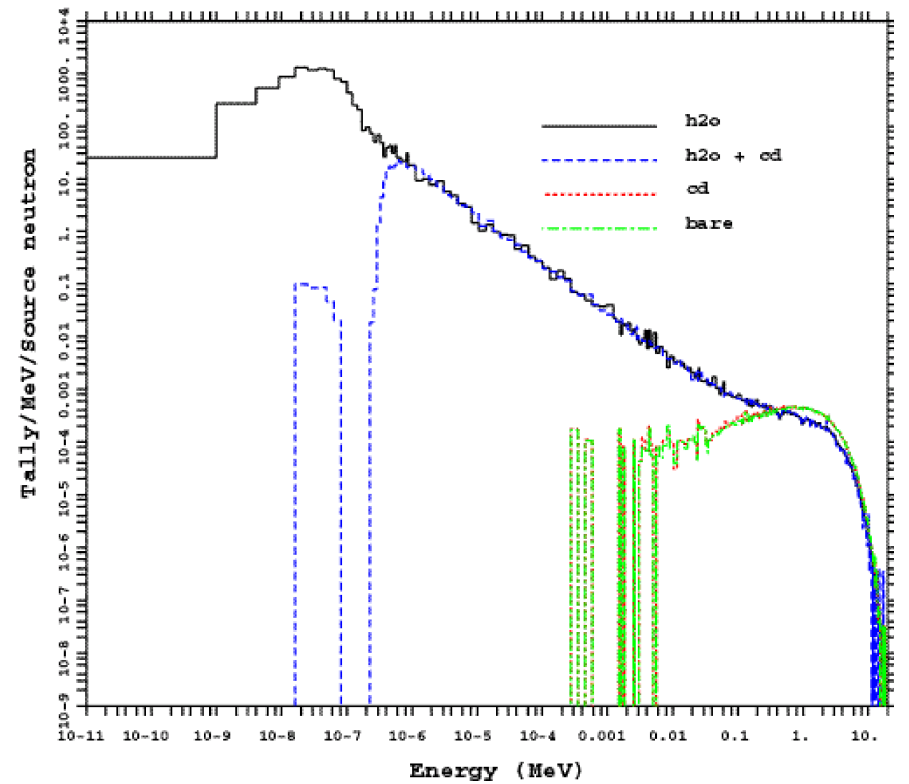

Fig. 2. Neutron flux spectra for the 5.08-cm (2-in.)-sphere experiments at the response foil locations. 


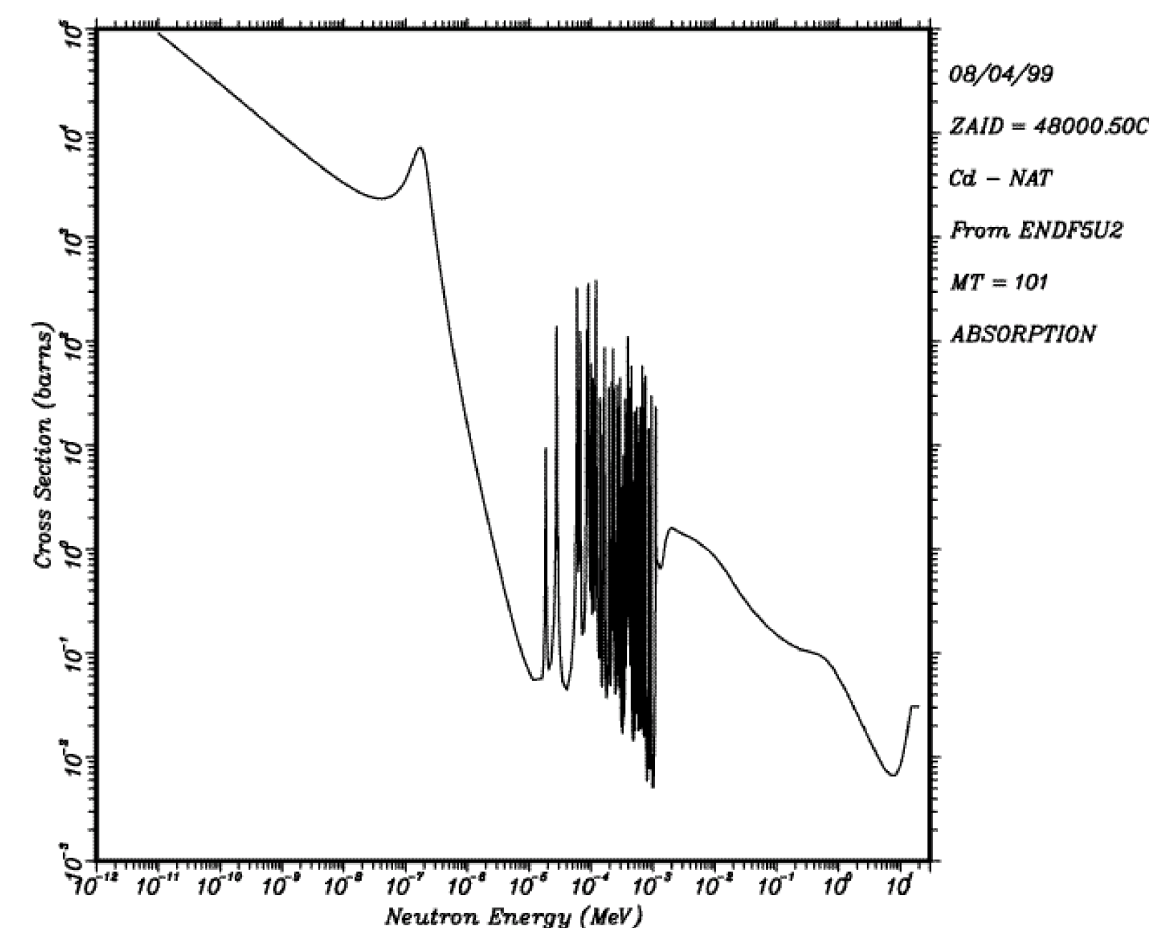

Fig. 3. Total absorption cross section for cadmium from ENDF/B-V.

\subsection{COMPARISON TO PREVIOUS ENDF/B-V RESULTS}

First, the results from the experiments and original calculations 1 are compared with the current results for the same ENDF/B-V response fission cross sections and are given in Table 2. The original calculations were performed using ENDF/B-V data for the neutron transport, with ENDL85 for platinum. As described in the previous section, the current calculations are based primarily on ENDF/B-VI data for neutron transport. The results in Table 2 for both the original and current MCNP calculations use the same ENDF/B-V data for calculating the response fission rates at the foil positions for ${ }^{235} \mathrm{U},{ }^{238} \mathrm{U},{ }^{237} \mathrm{~Np}$, and ${ }^{239} \mathrm{Pu}$ and the same 45 -group NIST ${ }^{252} \mathrm{Cf}$ source specification. From these results no clear pattern emerges. The average $\mathrm{C} / \mathrm{E}$ ratio for the original calculations was 0.977 , with an average deviation of 0.032. The average $\mathrm{C} / \mathrm{E}$ ratio for the current calculations was also 0.977 , with an average deviation of 0.033. Similar behavior was observed for each nuclide of interest; there were no appreciable differences between the original and current calculations. 


\subsection{CURRENT MCNP CALCULATIONS}

Simulations of the NIST experiments were performed using ENDF/B-V, ENDF/B-VI (ENDF60), ENDL92, and LLLDOS data to calculate the responses (i.e., fission-reaction rates for ${ }^{235} \mathrm{U},{ }^{238} \mathrm{U},{ }^{237} \mathrm{~Np}$, and ${ }^{239} \mathrm{Pu}$ ). For these MCNP calculations, the ENDF/B-VI data of the ENDF60 neutron-data library (with ENDF/B-V for $\mathrm{Cd}$ and ENDL92 for $\mathrm{Pt}$ ) were used for the neutron transport. The source specification was a continuous Watt fission spectrum for ${ }^{252} \mathrm{Cf}$, described in Appendix $\mathrm{H}$ of the MCNP manual, having $\mathrm{a}=1.025 \mathrm{MeV}$ and $\mathrm{b}=2.926 \mathrm{MeV}^{-1}$. Tables 3-6 list the results for ${ }^{235} \mathrm{U},{ }^{238} \mathrm{U}$, ${ }^{237} \mathrm{~Np}$, and ${ }^{239} \mathrm{Pu}$, respectively.

Overall, the data libraries did well in matching experiment for ${ }^{235} \mathrm{U}$. The MCNP results for ENDF/B-VI consistently underpredict the experiment compared with the ENDF/B-V data for the bare and Cd experiments. The same behavior is observed for the ENDL92 data relative to the LLLDOS data. The ENDF/B-V and B-VI data gave similar results for the water-moderated systems and underpredict the experiment relative to the LLNL-based data (i.e., ENDL92 and LLLDOS). The worst results relative to the experiment are for the smaller water-filled spheres and 1.5-in. water $+\mathrm{Cd}$ sphere experiment. 
Table 2. Comparison of original (ENDF/B-V) and current (ENDF/B-VI) transport calculations with experiment

(For the same ENDF/B-V response fission cross sections and the same NIST Cf-source spectrum)

\begin{tabular}{|c|c|c|c|c|c|c|c|c|c|}
\hline Isotope & Configuration & $\begin{array}{l}\text { Radius } \\
(\mathrm{mm})\end{array}$ & (in.) & $\begin{array}{l}\text { NIST } \\
\text { Experim } \\
\text { (barns) }\end{array}$ & $\mathrm{RE}^{a}$ & $\begin{array}{l}\text { Origina } \\
\text { MCNP } \\
\text { C/E }\end{array}$ & $\mathrm{RE}$ & $\begin{array}{l}\text { Current } \\
\text { MCNP } \\
\text { C/E }\end{array}$ & $\mathrm{RE}$ \\
\hline \multirow[t]{12}{*}{${ }^{235} \mathrm{U}$} & bare & 38.1 & 1.5 & 1.278 & 0.016 & 1.009 & 0.019 & 1.006 & 0.016 \\
\hline & bare & 50.8 & 2 & 1.279 & 0.016 & 1.009 & 0.019 & 1.006 & 0.016 \\
\hline & bare & 63.5 & 2.5 & & & & & & \\
\hline & $\mathrm{Cd}$ & 38.1 & 1.5 & 1.288 & 0.018 & 1.004 & 0.021 & 1.004 & 0.018 \\
\hline & $\mathrm{Cd}$ & 50.8 & 2 & 1.291 & 0.018 & 1.002 & 0.020 & 1.003 & 0.018 \\
\hline & $\mathrm{Cd}$ & 63.5 & 2.5 & & & & & & \\
\hline & $\mathrm{H}_{2} \mathrm{O}$ & 38.1 & 1.5 & 19.6 & 0.017 & 1.010 & 0.023 & 1.046 & 0.019 \\
\hline & $\mathrm{H}_{2} \mathrm{O}$ & 50.8 & 2 & 45.7 & 0.017 & 1.044 & 0.020 & 1.020 & 0.017 \\
\hline & $\mathrm{H}_{2} \mathrm{O}$ & 63.5 & 2.5 & 72.2 & 0.017 & 1.022 & 0.023 & 1.042 & 0.017 \\
\hline & $\mathrm{H}_{2} \mathrm{O}+\mathrm{Cd}$ & 38.1 & 1.5 & 4.18 & 0.017 & 1.024 & 0.023 & 1.037 & 0.017 \\
\hline & $\mathrm{H}_{2} \mathrm{O}+\mathrm{Cd}$ & 50.8 & 2 & 5.51 & 0.017 & 1.049 & 0.029 & 1.022 & 0.017 \\
\hline & $\mathrm{H}_{2} \mathrm{O}+\mathrm{Cd}$ & 63.5 & 2.5 & 5.86 & 0.017 & 1.109 & 0.026 & 1.048 & 0.017 \\
\hline \multirow[t]{12}{*}{${ }^{238} \mathrm{U}$} & bare & 38.1 & 1.5 & 0.332 & 0.017 & 0.946 & 0.021 & 0.945 & 0.017 \\
\hline & bare & 50.8 & 2 & 0.334 & 0.017 & 0.940 & 0.020 & 0.940 & 0.017 \\
\hline & bare & 63.5 & 2.5 & & & & & & \\
\hline & $\mathrm{Cd}$ & 38.1 & 1.5 & 0.333 & 0.018 & 0.940 & 0.022 & 0.936 & 0.018 \\
\hline & $\mathrm{Cd}$ & 50.8 & 2 & 0.334 & 0.018 & 0.937 & 0.021 & 0.934 & 0.018 \\
\hline & $\mathrm{Cd}$ & 63.5 & 2.5 & & & & & & \\
\hline & $\mathrm{H}_{2} \mathrm{O}$ & 38.1 & 1.5 & 0.228 & 0.018 & 0.961 & 0.025 & 0.945 & 0.018 \\
\hline & $\mathrm{H}_{2} \mathrm{O}$ & 50.8 & 2 & 0.199 & 0.018 & 0.935 & 0.020 & 0.944 & 0.018 \\
\hline & $\mathrm{H}_{2} \mathrm{O}$ & 63.5 & 2.5 & 0.172 & 0.018 & 0.942 & 0.021 & 0.950 & 0.018 \\
\hline & $\mathrm{H}_{2} \mathrm{O}+\mathrm{Cd}$ & 38.1 & 1.5 & 0.228 & 0.019 & 0.934 & 0.020 & 0.919 & 0.019 \\
\hline & $\mathrm{H}_{2} \mathrm{O}+\mathrm{Cd}$ & 50.8 & 2 & 0.199 & 0.019 & 0.930 & 0.027 & 0.928 & 0.019 \\
\hline & $\mathrm{H}_{2} \mathrm{O}+\mathrm{Cd}$ & 63.5 & 2.5 & 0.171 & 0.019 & 0.953 & 0.024 & 0.941 & 0.019 \\
\hline \multirow[t]{12}{*}{${ }^{237} \mathrm{~Np}$} & bare & 38.1 & 1.5 & 1.419 & 0.018 & 0.968 & 0.021 & 0.969 & 0.018 \\
\hline & bare & 50.8 & 2 & 1.42 & 0.018 & 0.968 & 0.020 & 0.969 & 0.018 \\
\hline & bare & 63.5 & 2.5 & & & & & & \\
\hline & $\mathrm{Cd}$ & 38.1 & 1.5 & 1.427 & 0.019 & 0.961 & 0.022 & 0.962 & 0.019 \\
\hline & $\mathrm{Cd}$ & 50.8 & 2 & 1.427 & 0.019 & 0.963 & 0.021 & 0.962 & 0.019 \\
\hline & $\mathrm{Cd}$ & 63.5 & 2.5 & & & & & & \\
\hline & $\mathrm{H}_{2} \mathrm{O}$ & 38.1 & 1.5 & 0.987 & 0.018 & 0.977 & 0.019 & 0.967 & 0.018 \\
\hline & $\mathrm{H}_{2} \mathrm{O}$ & 50.8 & 2 & 0.873 & 0.018 & 0.953 & 0.020 & 0.954 & 0.018 \\
\hline & $\mathrm{H}_{2} \mathrm{O}$ & 63.5 & 2.5 & 0.761 & 0.018 & 0.930 & 0.021 & 0.938 & 0.018 \\
\hline & $\mathrm{H}_{2} \mathrm{O}+\mathrm{Cd}$ & 38.1 & 1.5 & 1.011 & 0.019 & 0.936 & 0.020 & 0.927 & 0.019 \\
\hline & $\mathrm{H}_{2} \mathrm{O}+\mathrm{Cd}$ & 50.8 & 2 & 0.877 & 0.019 & 0.932 & 0.024 & 0.936 & 0.019 \\
\hline & $\mathrm{H}_{2} \mathrm{O}+\mathrm{Cd}$ & 63.5 & 2.5 & 0.748 & 0.019 & 0.952 & 0.022 & 0.945 & 0.019 \\
\hline \multirow[t]{12}{*}{${ }^{239} \mathrm{Pu}$} & bare & 38.1 & 1.5 & 1.916 & 0.015 & 0.970 & 0.018 & 0.969 & 0.015 \\
\hline & bare & 50.8 & 2 & 1.924 & 0.015 & 0.967 & 0.017 & 0.965 & 0.015 \\
\hline & bare & 63.5 & 2.5 & & & & & & \\
\hline & $\mathrm{Cd}$ & 38.1 & 1.5 & 1.934 & 0.018 & 0.964 & 0.021 & 0.964 & 0.018 \\
\hline & $\mathrm{Cd}$ & 50.8 & 2 & 1.931 & 0.018 & 0.966 & 0.020 & 0.966 & 0.018 \\
\hline & $\mathrm{Cd}$ & 63.5 & 2.5 & & & & & & \\
\hline & $\mathrm{H}_{2} \mathrm{O}$ & 38.1 & 1.5 & 36.7 & 0.015 & 1.011 & 0.027 & 1.019 & 0.015 \\
\hline & $\mathrm{H}_{2} \mathrm{O}$ & 50.8 & 2 & 82.3 & 0.015 & 1.038 & 0.020 & 1.007 & 0.015 \\
\hline & $\mathrm{H}_{2} \mathrm{O}$ & 63.5 & 2.5 & 125.5 & 0.015 & 1.010 & 0.021 & 1.029 & 0.015 \\
\hline & $\mathrm{H}_{2} \mathrm{O}+\mathrm{Cd}$ & 38.1 & 1.5 & 5.34 & 0.019 & 0.983 & 0.036 & 1.040 & 0.019 \\
\hline & $\mathrm{H}_{2} \mathrm{O}+\mathrm{Cd}$ & 50.8 & 2 & 7.04 & 0.019 & 0.959 & 0.034 & 0.984 & 0.019 \\
\hline & $\mathrm{H}_{2} \mathrm{O}+\mathrm{Cd}$ & 63.5 & 2.5 & 7.74 & 0.019 & 0.969 & 0.031 & 0.977 & 0.019 \\
\hline
\end{tabular}

${ }^{a}$ The relative error or fractional standard deviation in the Monte Carlo results. 


\section{Table 3. Comparison of MCNP calculations with various ${ }^{235} \mathrm{U}$ fission cross sections to NIST experimental measurements}

(For the same ENDF/B-VI transport calculation and the same Watt Cf fission spectrum)

\begin{tabular}{|c|c|c|c|c|c|c|c|c|c|c|}
\hline \multirow[b]{2}{*}{ Configuratior } & \multirow{2}{*}{$\begin{array}{l}\text { Radius } \\
(\mathrm{mm})\end{array}$} & \multirow[b]{2}{*}{ (in.) } & \multicolumn{2}{|c|}{ ENDF/B-V } & \multicolumn{2}{|c|}{ ENDF/B-VI } & \multicolumn{2}{|c|}{ ENDL92 } & \multicolumn{2}{|c|}{ LLLDOS } \\
\hline & & & $\mathrm{C} / \mathrm{E}$ & $\mathrm{RE}^{a}$ & $\mathrm{C} / \mathrm{E}$ & $\mathrm{RE}$ & $\mathrm{C} / \mathrm{E}$ & $\mathrm{RE}$ & $\mathrm{C} / \mathrm{E}$ & $\mathrm{RE}$ \\
\hline bare & 38.1 & 1.5 & 0.997 & 0.016 & 0.981 & 0.016 & 0.985 & 0.016 & 0.995 & 0.016 \\
\hline bare & 50.8 & 2 & 0.996 & 0.016 & 0.981 & 0.016 & 0.985 & 0.016 & 0.994 & 0.016 \\
\hline bare & 63.5 & 2.5 & & & & & & & & \\
\hline $\mathrm{Cd}$ & 38.1 & 1.5 & 0.994 & 0.018 & 0.978 & 0.018 & 0.982 & 0.018 & 0.991 & 0.018 \\
\hline $\mathrm{Cd}$ & 50.8 & 2 & 0.992 & 0.018 & 0.977 & 0.018 & 0.981 & 0.018 & 0.990 & 0.018 \\
\hline $\mathrm{Cd}$ & 63.5 & 2.5 & & & & & & & & \\
\hline $\mathrm{H}_{2} \mathrm{O}$ & 38.1 & 1.5 & 0.950 & 0.017 & 0.952 & 0.017 & 0.964 & 0.017 & 0.956 & 0.017 \\
\hline $\mathrm{H}_{2} \mathrm{O}$ & 50.8 & 2 & 0.944 & 0.018 & 0.947 & 0.018 & 0.960 & 0.018 & 0.957 & 0.018 \\
\hline $\mathrm{H}_{2} \mathrm{O}$ & 63.5 & 2.5 & 0.978 & 0.020 & 0.982 & 0.020 & 0.995 & 0.020 & 0.992 & 0.020 \\
\hline $\mathrm{H}_{2} \mathrm{O}+\mathrm{Cd}$ & 38.1 & 1.5 & 0.947 & 0.025 & 0.931 & 0.025 & 0.951 & 0.024 & 0.948 & 0.024 \\
\hline $\mathrm{H}_{2} \mathrm{O}+\mathrm{Cd}$ & 50.8 & 2 & 0.980 & 0.021 & 0.974 & 0.021 & 0.988 & 0.021 & 0.988 & 0.021 \\
\hline $\mathrm{H}_{2} \mathrm{O}+\mathrm{Cd}$ & 63.5 & 2.5 & 0.996 & 0.022 & 0.985 & 0.022 & 1.002 & 0.021 & 1.002 & 0.022 \\
\hline
\end{tabular}

${ }^{a}$ The relative error or fractional standard deviation in the Monte Carlo results.

\section{Table 4. Comparison of MCNP calculations with various ${ }^{238} \mathrm{U}$ response fission cross sections to NIST experimental measurements}

(For the same ENDF/B-VI transport calculation and the same Watt Cf fission spectrum)

\begin{tabular}{|c|c|c|c|c|c|c|c|c|c|c|}
\hline \multirow{2}{*}{ Configuration } & \multirow{2}{*}{$\begin{array}{l}\text { Radius } \\
(\mathrm{mm})\end{array}$} & \multirow[b]{2}{*}{ (in.) } & \multicolumn{2}{|c|}{ ENDF/B-V } & \multicolumn{2}{|c|}{ ENDF/B-VI } & \multicolumn{2}{|c|}{ ENDL92 } & \multicolumn{2}{|c|}{ LLLDOS } \\
\hline & & & $\mathrm{C} / \mathrm{E}$ & $\mathrm{RE}^{a}$ & $\mathrm{C} / \mathrm{E}$ & $\mathrm{RE}$ & $\mathrm{C} / \mathrm{E}$ & $\mathrm{RE}$ & $\mathrm{C} / \mathrm{E}$ & $\mathrm{RE}$ \\
\hline bare & 38.1 & 1.5 & 1.024 & 0.017 & 1.024 & 0.017 & 1.053 & 0.017 & 1.053 & 0.017 \\
\hline bare & 50.8 & 2 & 1.017 & 0.017 & 1.018 & 0.017 & 1.047 & 0.017 & 1.047 & 0.017 \\
\hline bare & 63.5 & 2.5 & & & & & & & & \\
\hline $\mathrm{Cd}$ & 38.1 & 1.5 & 1.015 & 0.018 & 1.016 & 0.018 & 1.045 & 0.018 & 1.045 & 0.018 \\
\hline $\mathrm{Cd}$ & 50.8 & 2 & 1.012 & 0.018 & 1.013 & 0.018 & 1.042 & 0.018 & 1.041 & 0.018 \\
\hline $\mathrm{Cd}$ & 63.5 & 2.5 & & & & & & & & \\
\hline $\mathrm{H}_{2} \mathrm{O}$ & 38.1 & 1.5 & 1.047 & 0.018 & 1.048 & 0.018 & 1.078 & 0.018 & 1.078 & 0.018 \\
\hline $\mathrm{H}_{2} \mathrm{O}$ & 50.8 & 2 & 1.054 & 0.018 & 1.054 & 0.018 & 1.083 & 0.018 & 1.083 & 0.018 \\
\hline $\mathrm{H}_{2} \mathrm{O}$ & 63.5 & 2.5 & 1.064 & 0.018 & 1.065 & 0.018 & 1.095 & 0.018 & 1.094 & 0.018 \\
\hline $\mathrm{H}_{2} \mathrm{O}+\mathrm{Cd}$ & 38.1 & 1.5 & 1.052 & 0.021 & 1.053 & 0.021 & 1.083 & 0.021 & 1.082 & 0.021 \\
\hline $\mathrm{H}_{2} \mathrm{O}+\mathrm{Cd}$ & 50.8 & 2 & 1.017 & 0.021 & 1.018 & 0.021 & 1.046 & 0.021 & 1.046 & 0.021 \\
\hline $\mathrm{H}_{2} \mathrm{O}+\mathrm{Cd}$ & 63.5 & 2.5 & 1.035 & 0.022 & 1.036 & 0.022 & 1.065 & 0.022 & 1.065 & 0.022 \\
\hline
\end{tabular}

${ }^{a}$ The relative error or fractional standard deviation in the Monte Carlo results. 
The MCNP calculations consistently overpredict the fission rates for ${ }^{238} \mathrm{U}$ for all four data libraries. The new ENDF/B-VI evaluation for ${ }^{238} \mathrm{U}$ did not change the MCNP calculations relative to ENDF/B-V results. The LLNL-based data of ENDL92 and LLLDOS gave equivalent results. The ENDF-based data more closely matched experiment for all experimental configurations. The worst results are for the water-filled spheres.

\section{Table 5. Comparison of MCNP calculations with various ${ }^{237} \mathrm{~Np}$ fission cross sections to NIST experimental measurements}

(For the same ENDF/B-VI transport calculation and the same Watt Cf fission spectrum)

\begin{tabular}{|c|c|c|c|c|c|c|c|c|c|c|}
\hline \multirow{2}{*}{ Configuration } & \multirow{2}{*}{$\begin{array}{l}\text { Radius } \\
(\mathrm{mm})\end{array}$} & \multirow[b]{2}{*}{ (in.) } & \multicolumn{2}{|c|}{ ENDF/B-V } & \multicolumn{2}{|c|}{ ENDF/B-VI } & \multicolumn{2}{|c|}{ ENDL92 } & \multicolumn{2}{|c|}{ LLLDOS } \\
\hline & & & $\mathrm{C} / \mathrm{E}$ & $\mathrm{RE}$ & $\mathrm{C} / \mathrm{E}$ & $\mathrm{RE}$ & $\mathrm{C} / \mathrm{E}$ & $\mathrm{RE}$ & $\mathrm{C} / \mathrm{E}$ & $\mathrm{RE}$ \\
\hline bare & 38.1 & 1.5 & 1.000 & 0.018 & 0.986 & 0.018 & 0.967 & 0.018 & 0.968 & 0.018 \\
\hline bare & 50.8 & 2 & 0.999 & 0.018 & 0.986 & 0.018 & 0.967 & 0.018 & 0.967 & 0.018 \\
\hline bare & 63.5 & 2.5 & & & & & & & & \\
\hline $\mathrm{Cd}$ & 38.1 & 1.5 & 0.992 & 0.019 & 0.979 & 0.019 & 0.960 & 0.019 & 0.961 & 0.019 \\
\hline $\mathrm{Cd}$ & 50.8 & 2 & 0.993 & 0.019 & 0.979 & 0.019 & 0.961 & 0.019 & 0.962 & 0.019 \\
\hline $\mathrm{Cd}$ & 63.5 & 2.5 & & & & & & & & \\
\hline $\mathrm{H}_{2} \mathrm{O}$ & 38.1 & 1.5 & 1.029 & 0.018 & 1.015 & 0.018 & 1.012 & 0.018 & 1.013 & 0.018 \\
\hline $\mathrm{H}_{2} \mathrm{O}$ & 50.8 & 2 & 1.020 & 0.018 & 1.007 & 0.018 & 1.012 & 0.018 & 1.013 & 0.018 \\
\hline $\mathrm{H}_{2} \mathrm{O}$ & 63.5 & 2.5 & 1.020 & 0.018 & 1.006 & 0.018 & 1.017 & 0.019 & 1.018 & 0.019 \\
\hline $\mathrm{H}_{2} \mathrm{O}+\mathrm{Cd}$ & 38.1 & 1.5 & 1.007 & 0.021 & 0.994 & 0.021 & 0.990 & 0.021 & 0.991 & 0.021 \\
\hline $\mathrm{H}_{2} \mathrm{O}+\mathrm{Cd}$ & 50.8 & 2 & 0.996 & 0.020 & 0.982 & 0.020 & 0.990 & 0.020 & 0.991 & 0.020 \\
\hline $\mathrm{H}_{2} \mathrm{O}+\mathrm{Cd}$ & 63.5 & 2.5 & 1.014 & 0.020 & 1.001 & 0.020 & 1.012 & 0.020 & 1.013 & 0.020 \\
\hline
\end{tabular}

The ENDF/B-VI results for ${ }^{237} \mathrm{~Np}$ consistently underpredicted the experiment for the bare sphere and cadmium measurements, and were consistently lower than the ENDF/B-V results. The ENDF/B-VI results for the water-moderated spheres more closely matched experiment relative to the ENDF/B-V results. The ENDL92 and LLLDOS results were equivalent, yet farther from the experiment results for both the bare-sphere and cadmium measurements relative to ENDF. 
Table 6. Comparison of MCNP calculations with various ${ }^{239} \mathrm{Pu}$ response fission cross sections to NIST experimental measurements

(For the same ENDF/B-VI transport calculation and the same Watt Cf fission spectrum)

\begin{tabular}{|c|c|c|c|c|c|c|c|c|c|c|}
\hline \multirow{2}{*}{ Configuration } & \multicolumn{2}{|l|}{ Radius } & \multicolumn{2}{|c|}{ ENDF/B-V } & \multicolumn{2}{|c|}{ ENDF/B-VI } & \multicolumn{2}{|c|}{ ENDL92 } & \multicolumn{2}{|c|}{ LLLDOS } \\
\hline & $(\mathrm{mm})$ & (in.) & $\mathrm{C} / \mathrm{E}$ & RE & $\mathrm{C} / \mathrm{E}$ & RE & $\mathrm{C} / \mathrm{E}$ & RE & $\mathrm{C} / \mathrm{E}$ & RE \\
\hline bare & 38.1 & 1.5 & 0.967 & 0.015 & 0.965 & 0.015 & 0.955 & 0.015 & 0.960 & 0.015 \\
\hline bare & 50.8 & 2 & 0.963 & 0.015 & 0.961 & 0.015 & 0.951 & 0.015 & 0.956 & 0.015 \\
\hline bare & 63.5 & 2.5 & & & & & & & & \\
\hline $\mathrm{Cd}$ & 38.1 & 1.5 & 0.961 & 0.018 & 0.959 & 0.018 & 0.949 & 0.018 & 0.954 & 0.018 \\
\hline $\mathrm{Cd}$ & 50.8 & 2 & 0.963 & 0.018 & 0.961 & 0.018 & 0.951 & 0.018 & 0.957 & 0.018 \\
\hline $\mathrm{Cd}$ & 63.5 & 2.5 & & & & & & & & \\
\hline $\mathrm{H}_{2} \mathrm{O}$ & 38.1 & 1.5 & 0.919 & 0.016 & 0.925 & 0.016 & 0.941 & 0.016 & 0.936 & 0.016 \\
\hline $\mathrm{H}_{2} \mathrm{O}$ & 50.8 & 2 & 0.926 & 0.017 & 0.932 & 0.017 & 0.952 & 0.017 & 0.956 & 0.017 \\
\hline $\mathrm{H}_{2} \mathrm{O}$ & 63.5 & 2.5 & 0.953 & 0.019 & 0.959 & 0.019 & 0.981 & 0.019 & 0.984 & 0.019 \\
\hline $\mathrm{H}_{2} \mathrm{O}+\mathrm{Cd}$ & 38.1 & 1.5 & 0.918 & 0.033 & 0.919 & 0.033 & 0.923 & 0.032 & 0.974 & 0.027 \\
\hline $\mathrm{H}_{2} \mathrm{O}+\mathrm{Cd}$ & 50.8 & 2 & 0.983 & 0.026 & 0.975 & 0.026 & 0.980 & 0.025 & 0.992 & 0.022 \\
\hline $\mathrm{H}_{2} \mathrm{O}+\mathrm{Cd}$ & 63.5 & 2.5 & 0.919 & 0.026 & 0.911 & 0.026 & 0.932 & 0.025 & 0.979 & 0.022 \\
\hline
\end{tabular}

${ }^{a}$ The relative error or fractional standard deviation in the Monte Carlo results.

The results for ${ }^{239} \mathrm{Pu}$ were remarkably similar for the four data libraries. The MCNP calculations consistently underpredict the measurements, particularly for the water-moderated spheres. 


\section{APPLICATION OF GLLSM TOOLS TO NIST WATER SPHERES}

The results shown in the previous section are not uncommon when detailed comparisons of measured and calculated values are performed using multiple-source spectra and cross-section sets. The wide variation in the predicted $\mathrm{C} / \mathrm{E}$ values indicates a substantial amount of uncertainty that is not properly accounted for in the experimental and Monte Carlo uncertainties alone. To properly understand these results, the quantification and/or inclusion of each of the uncertainty effects needs to be achieved. For this task, a subset of the complete results shown in the previous section is selected. The ENDF/B-V transport and fission cross sections, along with the NIST-supplied fission spectrum, are used in this portion of the analysis. The selection of ENDF/B-V was primarily due to the availability of cross-section uncertainty information for the major cross-section constituents. Although the Monte Carlo uncertainties could have been explicitly included, if desired, we preferred to reduce them. The results were recalculated with a higher degree of precision (i.e., smaller Monte Carlo standard deviations), such that the code uncertainties could be ignored in comparison with the remaining uncertainties.

The measured values of the average fission cross sections, for each of the "wet" configurations, are repeated in Table 7, alongside their respective relative experimental uncertainties. These uncertainties are correlated, of course, and the correlations will be considered in some of the analyses. The calculated values were obtained by MCNP using ENDF/B-V cross sections and the same detailed model of the water spheres used previously. The calculated values and their corresponding relative uncertainties, reflecting the propagated cross-section uncertainties, ${ }^{12}$ are also shown in Table 7 . The last two columns of Table 7 are the combined relative uncertainty of the deviation of the corresponding measured and calculated values and the respective "individual $\chi^{2}$." This quantity is a measure of the consistency of a particular experimental value with its corresponding calculated value reflecting all relevant uncertainties and preferably should be close to unity. The entries in Table 7 are organized as 
groups of six measurements of the same reaction rate. Within each group, the first three entries are of measurements with uncovered fission foils and the last three of cadmium-covered foils. In each subgroup of three measurements, the entries are arranged according to increasing water-sphere diameters of 3-, 4and 5-in. (radii of 3.81, 5.08, and $6.35 \mathrm{~cm}$ ), respectively. The content of Table 7 is also represented graphically in Figs. 4 and 5.

In Fig. 4, the relative deviations of the calculated from the measured values are represented as diamonds for each of the 24 experiments. The band of the relative experimental uncertainties is depicted by the dashed green curves and the corresponding bands of the calculated and total relative uncertainties are represented by the blue and purple curves, respectively. Most relative deviations of the measured and calculated ${ }^{239} \mathrm{Pu}$ average cross-section values (entries 7-12) are within their respective experimental uncertainty and all of them are within their corresponding calculated uncertainty and are thus consistent. Although all the ${ }^{237} \mathrm{~Np}$ relative deviations (entries 19-24) are outside their experimental uncertainty band they are still consistent due to the high uncertainty of the ${ }^{237} \mathrm{~Np}$-fission cross section. As to ${ }^{238} \mathrm{U}$ (entries 13-18), not a single measurement is consistent with its calculated value. One should further notice that all the $\mathrm{Cd}$ covered ${ }^{235} \mathrm{U}$ values (entries 4-6) are also individually not consistent. All these observations can clearly be seen in Figure 5 in which the individual $\chi^{2}$ are plotted for each measurement.

In the analyses of more than a single measurement of the same type, even if the individual experimental uncertainties are not correlated, the calculated values are usually correlated. Since all the above measurements are related to each other, at least by the computational model and by the cross sections, and also via the use of the same experimental techniques, a joint consistency test is called for rather than looking only at the individual $\chi^{2}$ values. The joint consistency analysis is the subject of the next section. 
Table 7. Various measured and calculated average fission cross sections outside NIST water spheres driven by a central ${ }^{252} \mathrm{Cf}$ spontaneous fission neutron source

\begin{tabular}{|c|c|c|c|c|c|c|c|c|}
\hline $\mathrm{N}$ & $\begin{array}{c}\text { Response } \\
\left\langle\sigma_{\mathrm{f}}\right\rangle\end{array}$ & $\begin{array}{c}\text { Water } \\
\text { radius } \\
(\mathrm{cm})\end{array}$ & $\begin{array}{c}\text { Exp. } \\
\text { value } \\
\text { (barns) }\end{array}$ & $\begin{array}{l}\text { Exp. } \\
\text { unc. } \\
\text { (\%) }\end{array}$ & $\begin{array}{l}\text { Cal. value } \\
\text { (barns) }\end{array}$ & $\begin{array}{c}\text { Cal. } \\
\text { unc. }(\%)\end{array}$ & $\begin{array}{c}(\mathrm{E}-\mathrm{C}) / \mathrm{C} \\
\text { unc. }(\%)\end{array}$ & Individual $^{a} \chi^{2}$ \\
\hline 1 & ${ }^{235} \mathrm{U}$ & 3.81 & 19.6 & 1.7 & 20.40 & 2.41 & 2.95 & 1.77 \\
\hline 2 & ${ }^{235} \mathrm{U}$ & 5.08 & 45.7 & 1.7 & 46.68 & 2.19 & 2.77 & 0.58 \\
\hline 3 & ${ }^{235} \mathrm{U}$ & 6.35 & 72.2 & 1.7 & 72.23 & 1.99 & 2.62 & 0.00 \\
\hline 4 & ${ }^{235} \mathrm{U}^{b}$ & 3.81 & 4.18 & 1.7 & 4.404 & 2.59 & 3.09 & 2.70 \\
\hline 5 & ${ }^{235} \mathrm{U}^{b}$ & 5.08 & 5.51 & 1.7 & 5.774 & 2.66 & 3.16 & 2.10 \\
\hline 6 & ${ }^{235} \mathrm{U}^{b}$ & 6.35 & 5.86 & 1.7 & 6.104 & 2.65 & 3.15 & 1.61 \\
\hline 7 & ${ }^{239} \mathrm{Pu}$ & 3.81 & 36.7 & 1.5 & 37.28 & 2.43 & 2.86 & 0.30 \\
\hline 8 & ${ }^{239} \mathrm{Pu}$ & 5.08 & 82.3 & 1.5 & 82.61 & 2.21 & 2.67 & 0.02 \\
\hline 9 & ${ }^{239} \mathrm{Pu}$ & 6.35 & 125.5 & 1.5 & 124.2 & 2.03 & 2.53 & 0.17 \\
\hline 10 & ${ }^{239} \mathrm{Pu}{ }^{b}$ & 3.81 & 5.34 & 1.9 & 5.183 & 3.53 & 4.01 & 0.57 \\
\hline 11 & ${ }^{239} \mathrm{Pu}{ }^{b}$ & 5.08 & 7.04 & 1.9 & 6.935 & 3.73 & 4.18 & 0.13 \\
\hline 12 & ${ }^{239} \mathrm{Pu}{ }^{b}$ & 6.35 & 7.74 & 1.9 & 7.728 & 3.80 & 4.25 & 0.00 \\
\hline 13 & ${ }^{238} \mathrm{U}$ & 3.81 & 0.228 & 1.8 & 0.2127 & 2.06 & 2.74 & 6.90 \\
\hline 14 & ${ }^{238} \mathrm{U}$ & 5.08 & 0.199 & 1.8 & 0.1847 & 2.10 & 2.77 & 7.82 \\
\hline 15 & ${ }^{238} \mathrm{U}$ & 6.35 & 0.172 & 1.8 & 0.1600 & 2.15 & 2.81 & 7.14 \\
\hline 16 & ${ }^{238} \mathrm{U}^{b}$ & 3.81 & 0.228 & 1.9 & 0.2114 & 2.07 & 2.81 & 7.83 \\
\hline 17 & ${ }^{238} \mathrm{U}^{b}$ & 5.08 & 0.199 & 1.9 & 0.1846 & 2.11 & 2.84 & 7.56 \\
\hline 18 & ${ }^{238} \mathrm{U}^{b}$ & 6.35 & 0.171 & 1.9 & 0.1599 & 2.15 & 2.87 & 5.84 \\
\hline 19 & ${ }^{237} \mathrm{~Np}$ & 3.81 & 0.987 & 1.8 & 0.9436 & 9.11 & 9.28 & 0.25 \\
\hline 20 & ${ }^{237} \mathrm{~Np}$ & 5.08 & 0.873 & 1.8 & 0.8182 & 9.06 & 9.24 & 0.53 \\
\hline 21 & ${ }^{237} \mathrm{~Np}$ & 6.35 & 0.761 & 1.8 & 0.7038 & 9.02 & 9.19 & 0.78 \\
\hline 22 & ${ }^{237} \mathrm{~Np}^{b}$ & 3.81 & 1.011 & 1.9 & 0.9440 & 9.12 & 9.32 & 0.58 \\
\hline 23 & ${ }^{237} \mathrm{~Np}{ }^{b}$ & 5.08 & 0.877 & 1.9 & 0.8200 & 9.09 & 9.28 & 0.56 \\
\hline 24 & ${ }^{237} \mathrm{~Np}{ }^{b}$ & 6.35 & 0.748 & 1.9 & 0.7019 & 9.05 & 9.24 & 0.50 \\
\hline
\end{tabular}

${ }^{a}$ Defined as the square of the ratio of (E-C)/C to its uncertainty.

${ }^{b}$ Cd-covered fission foil. 


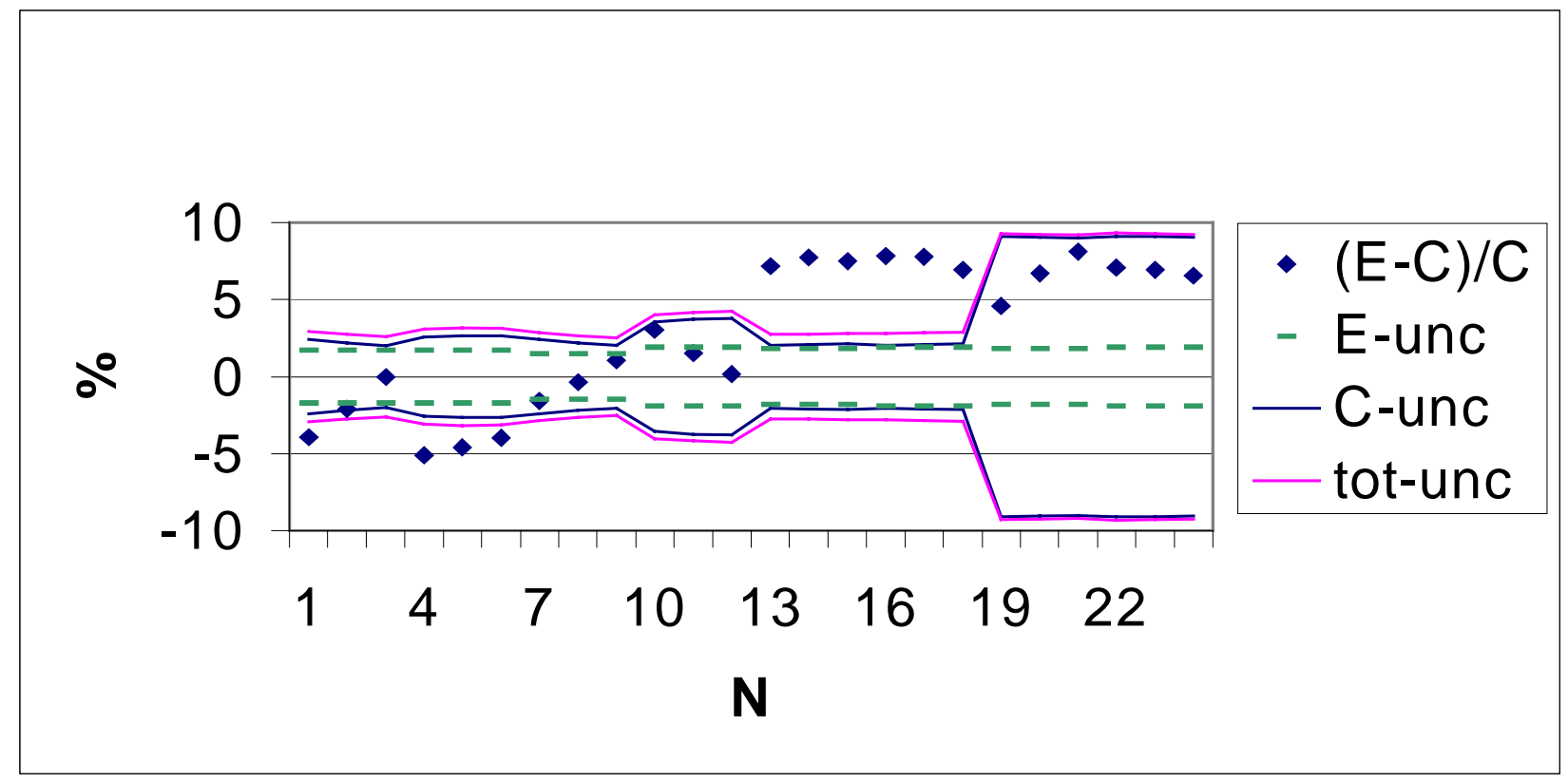

Fig. 4. The relative deviations and uncertainties of measured (E) from calculated (C) average fission cross sections outside NIST water spheres driven by a central ${ }^{252} \mathrm{Cf}$ spontaneous fission neutron source.

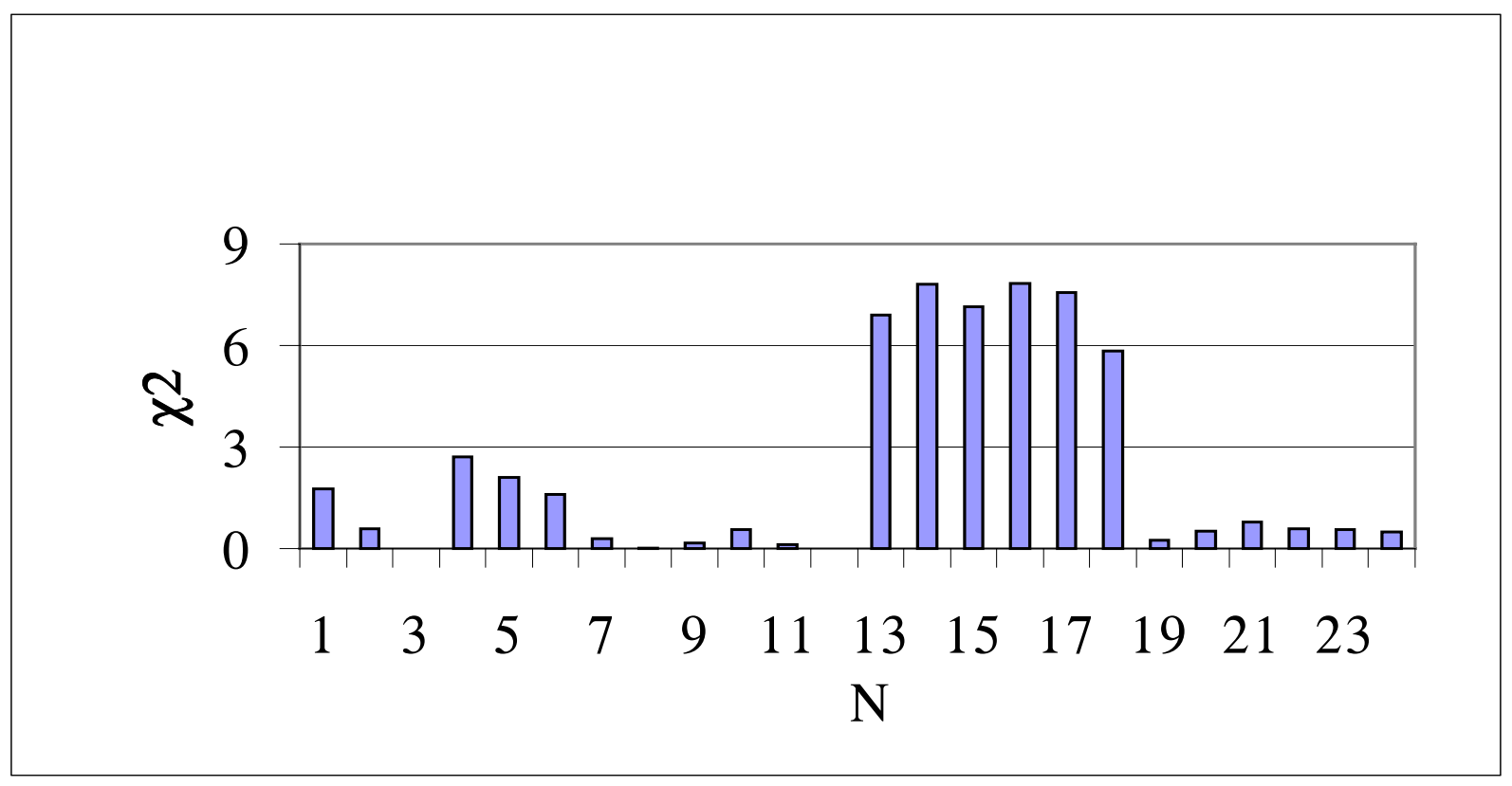

Fig. 5. Individual chi square values for various measured and calculated average fission cross sections measured outside NIST water spheres driven by a central ${ }^{252} \mathrm{Cf}$ spontaneous fission neutron source. 


\subsection{JOINT CONSISTENCY ANALYSIS}

The joint consistency of measured integral responses and their calculated values, depending on differential parameters, is intimately related to the so-called generalized-least-squares "adjustment""13 (denoted GLLSM). Whether one places confidence in the parameter adjustment methodology, or not, an intelligent comparison of measured and calculated responses, depending on differential parameters, calls for the same procedure of using the respective, correlated, uncertainty data and all the relevant sensitivities of the responses to the parameters.

Figure 6 represents the results of an adjustment procedure, taking into account all measurements listed in Table 7. Here again the diamonds represent the relative deviations of the calculated values from their respective measured responses, (E-C)/C. The solid squares denote the relative deviations of the GLLSM-based adjusted values from the respective measured values, (E-A)/C. The experimental uncertainty band is denoted by the dashed green curves. In Fig. 6 we assume that all the measurement uncertainties are not correlated. The resulting uncertainty of each adjusted response (inner purple curve pair) is always less than or equal to the original experimental uncertainty and the corresponding uncertainty related to the calculation reflecting the propagated parameter uncertainty (outer blue curve pair). Note that in Fig. 6 all the adjusted responses are within the experimental uncertainty of the original experimental values.

Although only the total relative uncertainty is reported in the formal documentation of the measurements, the experimenters provided ${ }^{14}$ estimates of the contributions of the various uncertainty sources to the total relative uncertainty. The contribution of the ${ }^{252} \mathrm{Cf}$-source intensity to the total relative uncertainty of the average cross sections (reaction rates) is estimated as $1.2 \%$ and is common to all measurements. The contribution of the uncertainty in the geometry, which is also common to all measurements, contributes $0.3 \%$ for the "dry" (without the water) case and slightly more for the "wet" case. The mass assay uncertainty contributes $0.5 \%, 0.5 \%, 1.0 \%$ and $1.0 \%$ in the case of ${ }^{235} \mathrm{U},{ }^{239} \mathrm{Pu},{ }^{238} \mathrm{U}$ and ${ }^{237} \mathrm{~Np}$ reference foils, respectively, and slightly more for other foils. In order to see the effect of the 
correlations between measurements, rather than calculating the individual covariance between any two measurements, we assumed the same covariance of $1.334 \%^{2}$ (i.e., $1.78 \mathrm{E}-4$ between any two measurements). This value is the combination of $1.2 \%^{2}+0.3 \%^{2}+0.5 \%^{2}$, which are independent uncertainty sources common to all measurements. The results of an adjustment taking into account all the measured values and their correlation are shown in Fig. 7. Unlike the results of the adjustment described in Fig. 6, only three adjusted values lie now in the central ("adjusted") uncertainty band. Most adjusted values differ now from their respective original measured values by more than the respective experimental uncertainty, and the ${ }^{238} \mathrm{U}$ values lie even outside the calculation uncertainty band.

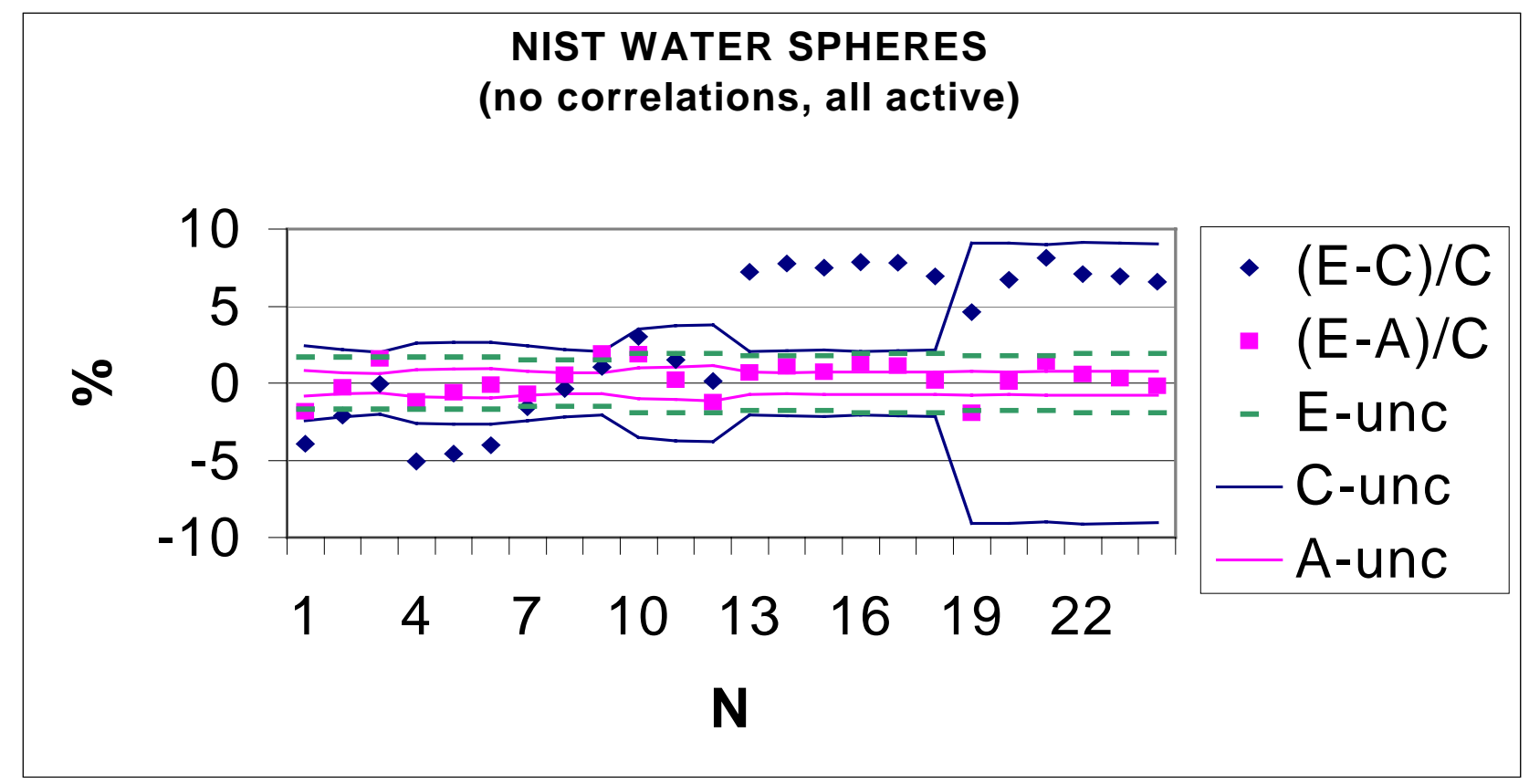

Fig. 6. The relative deviations and uncertainties of calculated (C) and adjusted (A) from measured (E) average fission cross sections outside NIST water spheres driven by a ${ }^{252} \mathrm{Cf}$ spontaneous fission neutron source. 


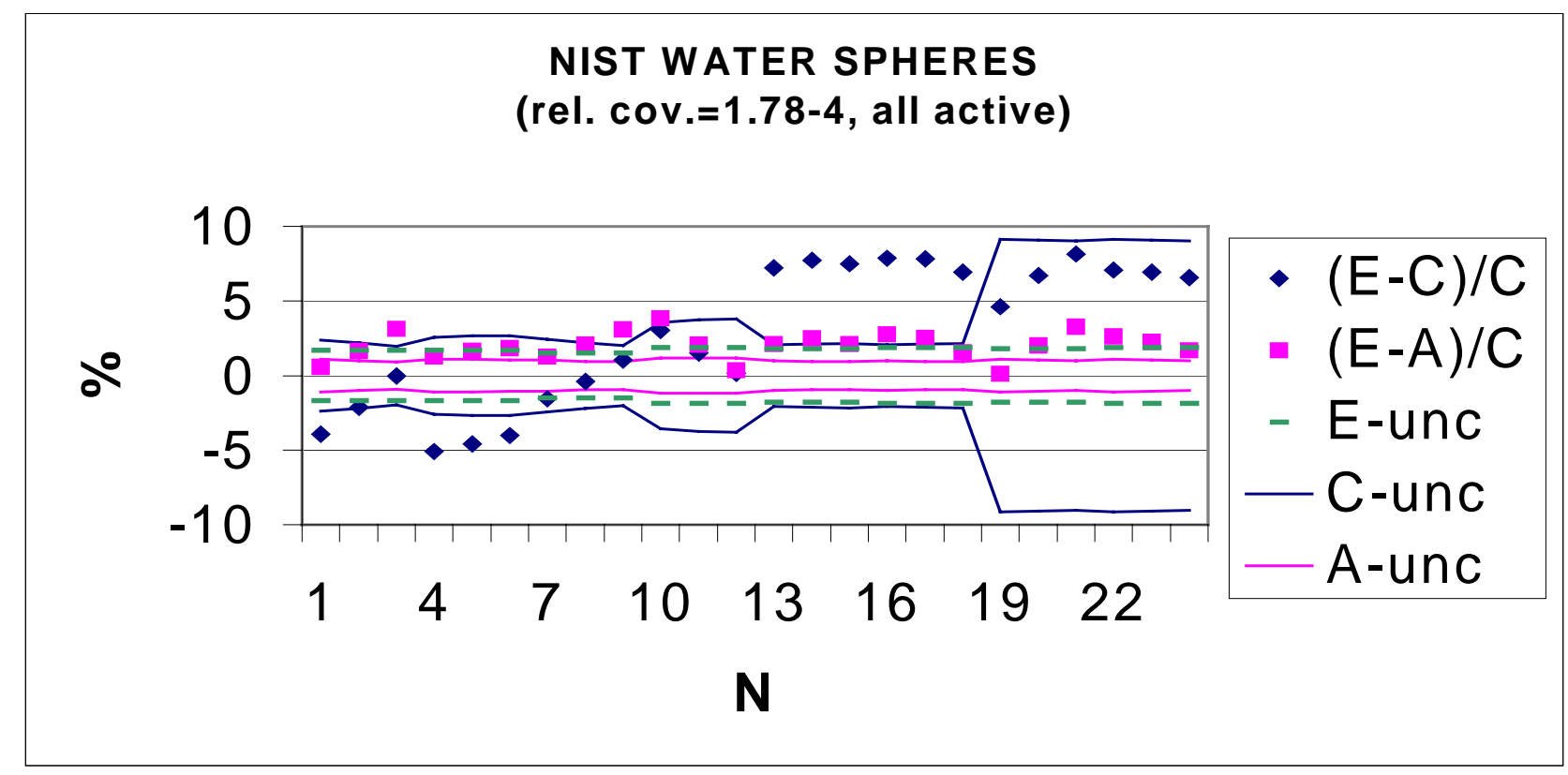

Fig. 7. The relative deviations and uncertainties of calculated (C) and adjusted (A) from measured ( $E$ ) average fission cross sections outside NIST water spheres driven by a central ${ }^{252} \mathrm{Cf}$ spontaneous fission neutron source. All measurements are correlated with each other.

Figures 8 and 9 show the results of an adjustment campaign where only the uncovered 3-in. measurements determine the adjustment (i.e., entries 1, 7,13 and 19). For all other measurements, the "adjusted" values were obtained by shifting the original calculated values according to the resulting cross-section adjustment and the respective sensitivities. In Fig. 8 no experimental correlation was considered, and in Fig. 9 the same relative covariance of $1.334 \%^{2}$ was used for all measured values. In both cases, it can be seen that the adjustment was quite effective for all measurements, although only one measurement, for each group of six, was active in the process. 


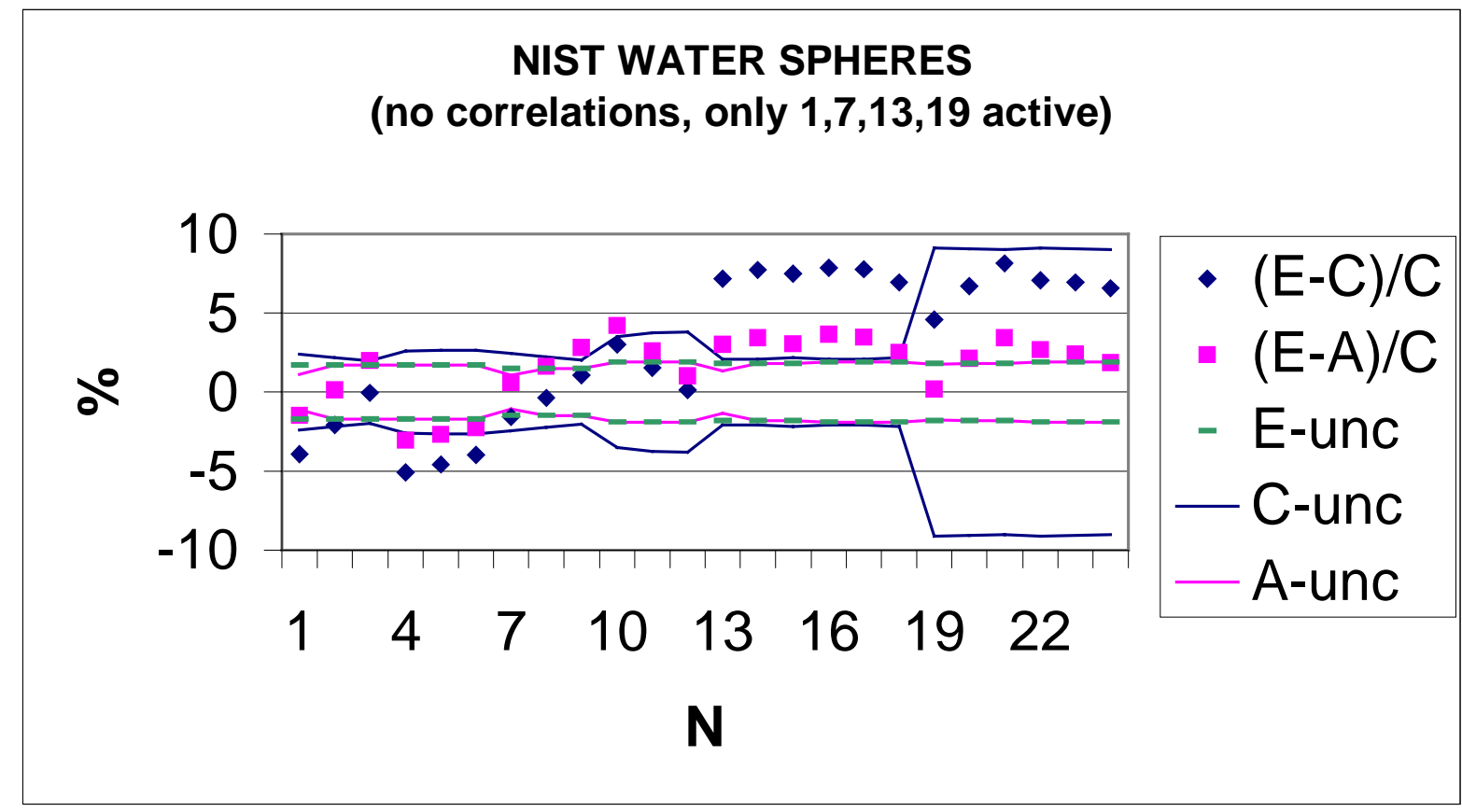

Fig. 8. The relative deviations and uncertainties of calculated (C) and adjusted (A) from measured (E) average fission cross sections outside NIST water spheres driven by a central ${ }^{252} \mathrm{Cf}$ spontaneous-fission neutrons source. (Only four measurements actively participated in the adjustment.)

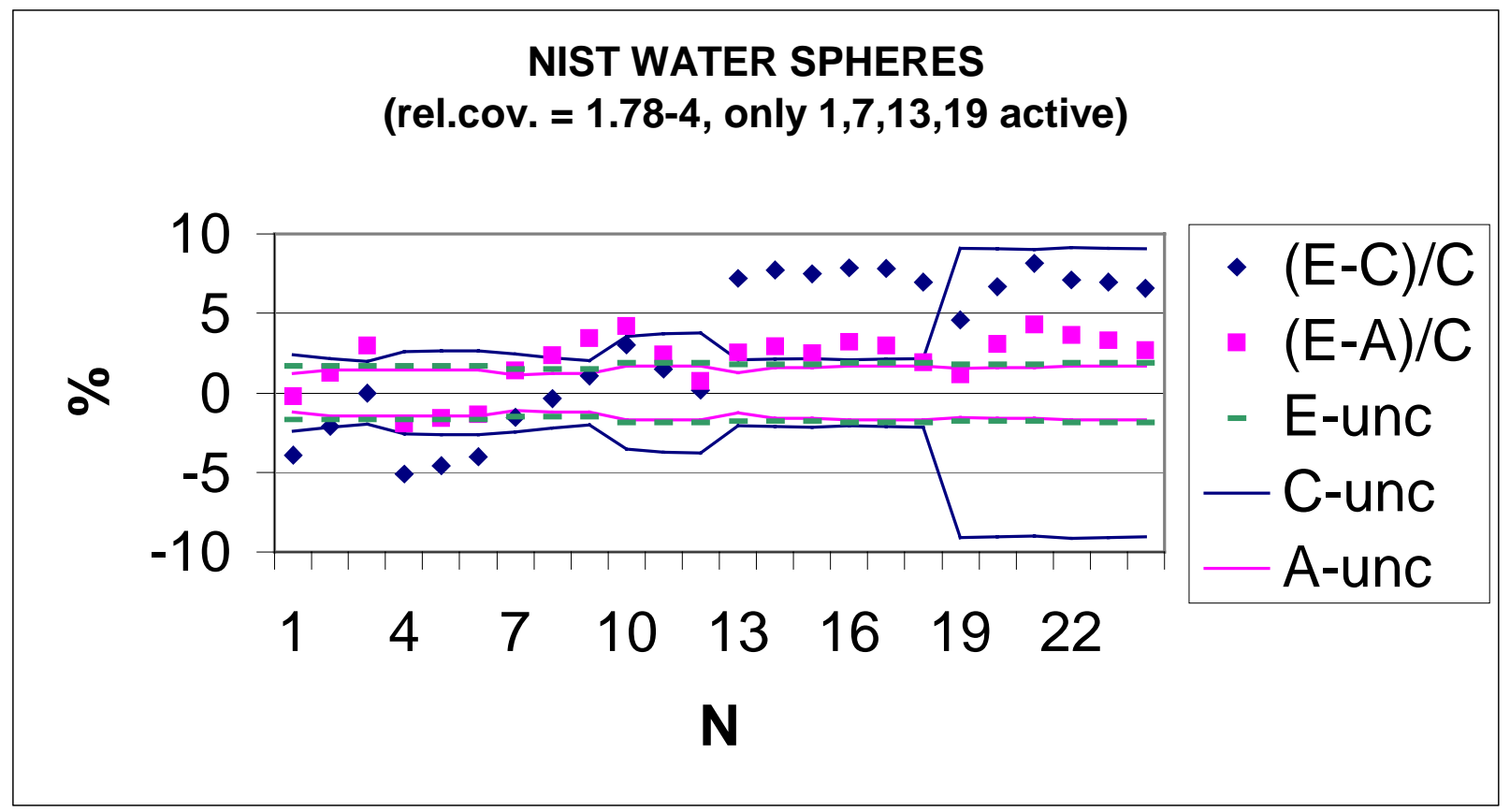

Fig. 9. The relative deviations and uncertainties of calculated $(C)$ and adjusted $(A)$ from measured $(E)$ average fission cross sections outside NIST water spheres driven by a central ${ }^{252} \mathrm{Cf}$ spontaneous-fission neutron source. (Only four measurements actively participated in the adjustment. All measurements are correlated.) 
Since the adjustment with only four measurements, one for each type of fission foil, was so effective, an attempt to perform an adjustment with only one active measurement was made. The results of this adjustment are shown in Fig. 10. Only measurement No. 1 (i.e., ${ }^{235} \mathrm{U}$ fission outside the 3-in. water sphere) was active in the adjustment process. This adjustment is not as successful as the previous one (i.e., Fig. 9) even for the other ${ }^{235} \mathrm{U}$ fission measurements. Whereas in Fig. 9 only one ${ }^{235} \mathrm{U}$ value is clearly outside the experimental uncertainty band, in Fig. 10 four out of six fall outside.

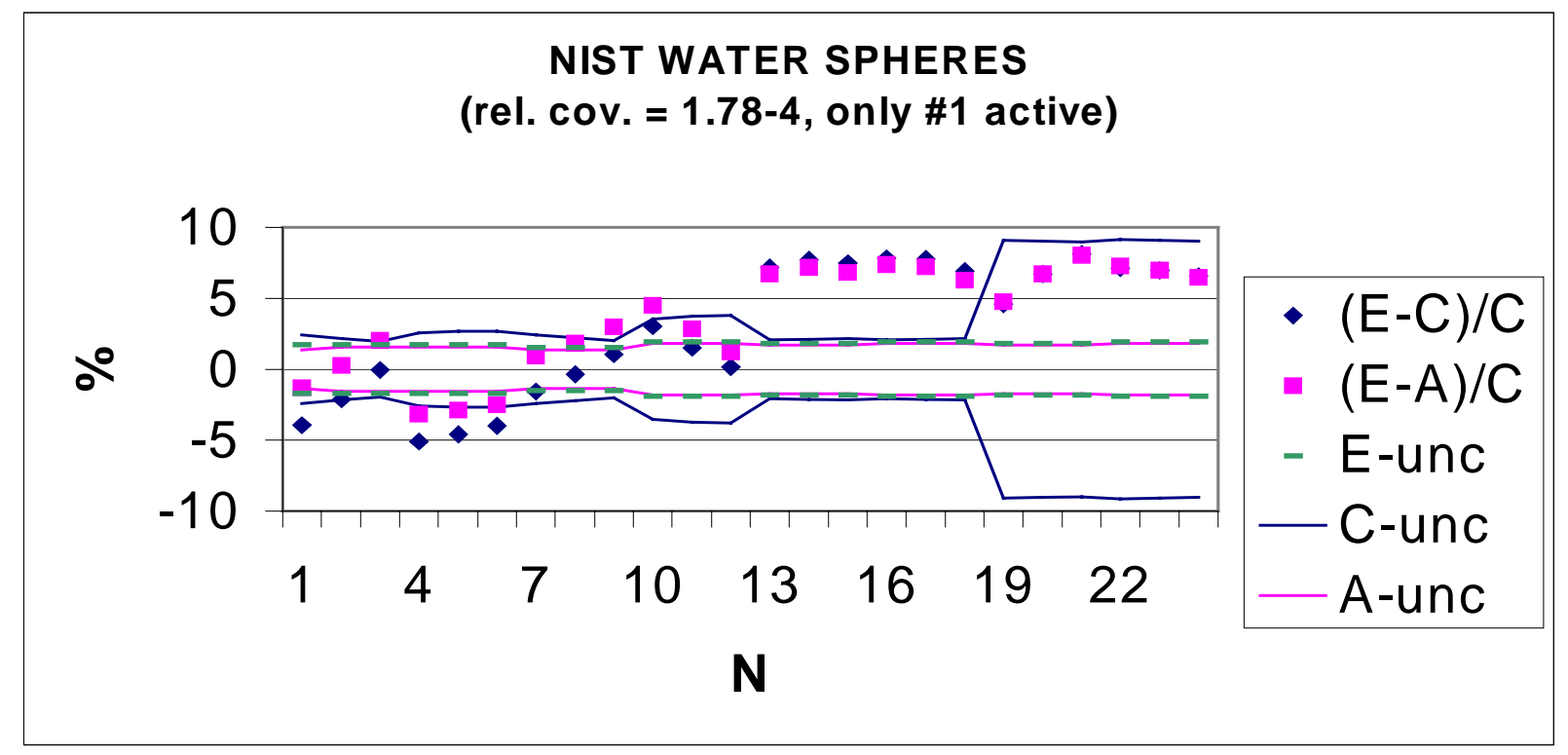

Fig. 10. The relative deviations and uncertainties of calculated $(C)$ and adjusted $(A)$ from measured (E) average fission cross sections outside NIST water spheres driven by a central ${ }^{252} \mathrm{Cf}$ spontaneous-fission neutron source. (Only one measurement actively participated in the adjustment. All measurements are correlated.) 
The effectiveness of the adjustment process is demonstrated very clearly in Figs. 11 and 12 . For each type of fission foil, the measurements outside the 3- and 5-in. water spheres were used for the adjustment process. The 4-in. measurements were modified only via the results of the adjustment utilizing the respective sensitivities. In Fig. 11, no correlation between the measurements was assumed, and in Fig. 12 these correlations were considered. Taking these correlations into account resulted in only three adjusted values within the central uncertainty band (A-unc), in contrast to half of the points in the case without the correlations, Fig. 11 .

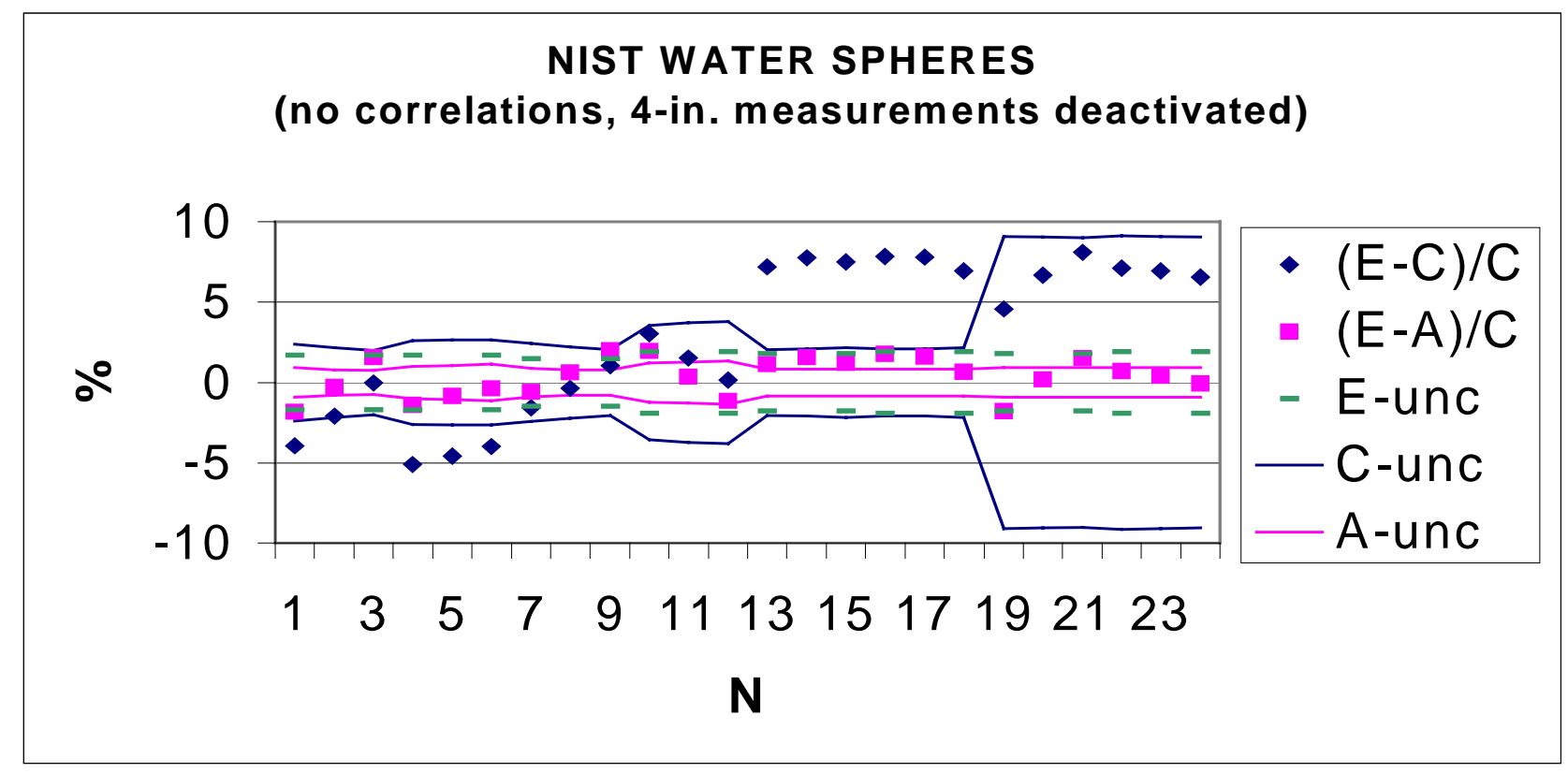

Fig. 11. The relative deviations and uncertainties of calculated $(C)$ and adjusted $(A)$ from measured (E) average fission cross sections outside NIST water spheres driven by ${ }^{252} \mathrm{Cf}$ spontaneous-fission neutrons at their center. (All measurements of the intermediate sphere did not actively participate in the adjustment.) 


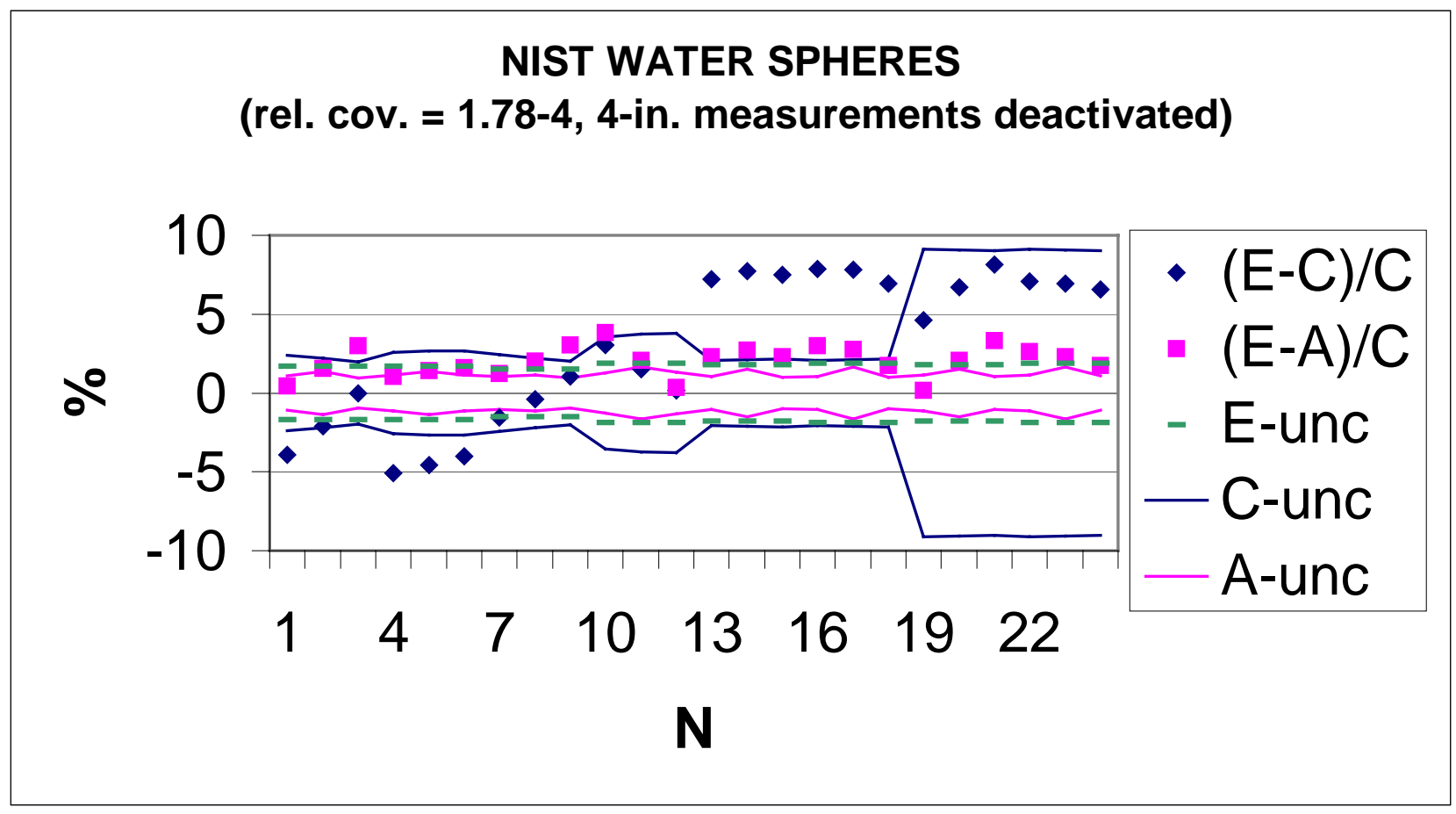

Fig. 12. The relative deviations and uncertainties of calculated (C) and adjusted (A) from measured (E) average fission cross sections outside NIST water spheres driven by a central ${ }^{252} \mathrm{Cf}$ spontaneous-fission neutron source. (All measurements of the intermediate sphere did not actively participate in the adjustment. All measurements are correlated.)

\subsection{QUALITATIVE COMPARISON OF GLLSM PREDICTED DATA CHANGES WITH RATIONAL EXPECTATIONS}

In the preceding section, the GLLSM procedure was referred to as a data-adjustment technique. Indeed, the results of the GLLSM procedure produce suggestions for data changes consistent with the data, with the measurements and with the calculations. The results reported thus far have given insight into the nature of the calculated-vs-measured differences, specifically identifying that the ${ }^{238} \mathrm{U}$ data have discrepancies that are not accounted for by the corresponding calculational and measurement uncertainties. The GLLSM data adjustments, in the cross sections and source spectrum, will now be qualitatively analyzed via a comparison of the trends seen in the measured-vs-calculated values.

The dry $\mathrm{C} / \mathrm{E}$ values of the average cross sections for the four fissionable materials depend primarily on the representation of the source fission spectrum and the respective fission cross sections. It 
is thus possible to suggest the hardness or softness of the input source spectrum. This prediction is possible because two of the materials $\left({ }^{238} \mathrm{U}\right.$ and $\left.{ }^{237} \mathrm{~Np}\right)$ have threshold-fission cross sections, while the other two $\left({ }^{235} \mathrm{U}\right.$ and $\left.{ }^{239} \mathrm{Pu}\right)$ have approximately flat fast-fission cross sections. Since the calculations in Sect. 3 of this report show that ENDF/B-VI and ENDF/B-V transport solutions produce approximately the same C/E values, the $\mathrm{C} / \mathrm{E}$ values in Table 2 (based on ENDF/B-VI or ENDF/B-V transport and ENDF/B-V response fission cross sections) can be compared with corresponding values in Tables 3-6 (based on ENDF/B-VI transport and various response fission cross sections). The bare-sphere C/E values for ${ }^{238} \mathrm{U}$ and ${ }^{237} \mathrm{~Np}$ are 0.94 and 0.96 (see Table 2), while they are 1.01-1.02 and 1.00, respectively, in Tables 4-5. The only difference between these values is in the input source spectrum, the former is based on the NIST-supplied ${ }^{252} \mathrm{Cf}$ spontaneous fission spectrum, and the latter is based on a Watt fission spectrum from the MCNP manual. The Watt spectrum is harder than the NIST spectrum and produces results more consistent with the measurements. The two spectra are displayed in Fig. 13, along with the suggested adjusted spectrum. Clearly, the adjusted spectrum is harder than the original NIST-supplied spectrum. However, the source spectrum should not move completely to the $\mathrm{MCNP}_{-}{ }^{252} \mathrm{Cf}$ spontaneousfission Watt spectrum, since one and the same source spectrum cannot give the correct reaction rates for the various isotopes fission cross sections with their varying energy dependence.

The resulting inability of the suggested source changes to correct the underprediction of the ${ }^{238} \mathrm{U}$ fission reactions necessitates an increase in the fission cross sections, particularly at high energies. The GLLSM predicts an increase in the ${ }^{238} \mathrm{U}$ fission cross sections in the $\mathrm{MeV}$ range of 3 to $8 \%$. Underpredictions for the ${ }^{239} \mathrm{Pu}$ and ${ }^{237} \mathrm{~Np}$ fission reaction rates for the bare cases shown in Table 2 also give rise to increases in the corresponding fission cross sections in the high-energy range around $1 \mathrm{MeV}$. Increases of 0.4 to $1.6 \%$ are predicted for ${ }^{239} \mathrm{Pu}$-fission cross sections over the entire energy range, while increases of 2 to $5 \%$ are indicated for ${ }^{237} \mathrm{~Np}$. 


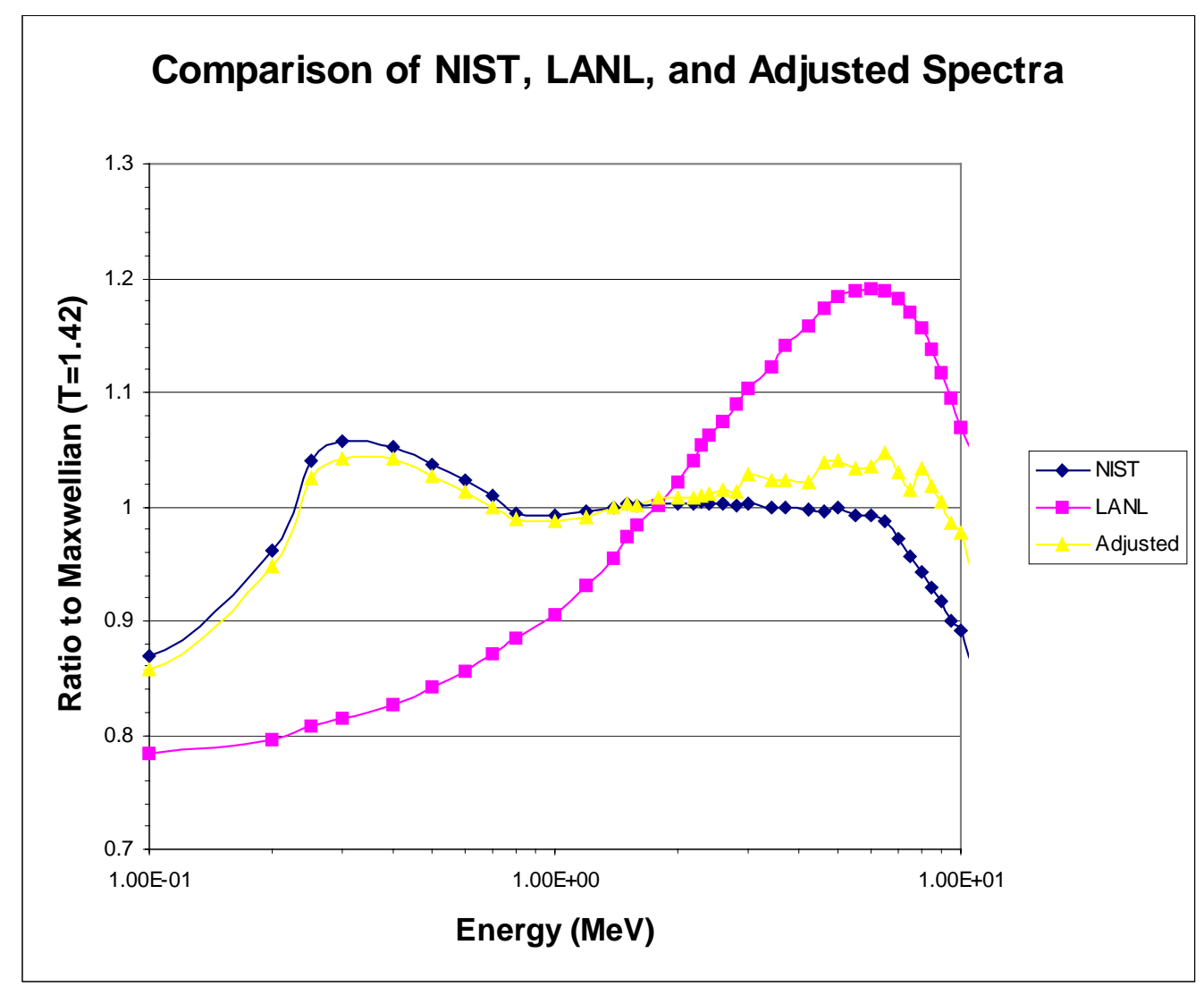

Fig. 13. Comparison of NIST-supplied, LANL continuous energy, and adjusted fission spectra for ${ }^{252} \mathrm{Cf}$.

Another trend that is evident from the results seen in Tables 2-6 is the increase in the predicted $\mathrm{C} / \mathrm{E}$ values with an increase in the water-sphere diameter. This trend was initially attributed to hydrogenscattering problems; however, note that these trends are largely absent in Table 2, which is based on the 45-group NIST spectrum. The trends are clearly seen in all but ${ }^{237} \mathrm{~Np}$ in Tables 3-6, which are based on the MCNP ${ }^{252} \mathrm{Cf}$ spontaneous-fission Watt spectrum. Thus, it can be argued that the effect is due to the same hardness in the fission spectrum, not a problem with the hydrogen scattering. The GLLSM results tend to confirm this in that the predicted changes in the hydrogen-scattering cross section (about $0.4 \%$ 
over the entire energy range) amount to only a $0.2 \%$ change in the calculated fission responses, not enough to account for the observed trends.

These GLLSM results, thus far, are based on only the wet cases. Analyses adding the dry results are planned in the future. However, a preliminary calculation was performed to assess potential differences between the wet and dry cases. Results show that, in general, the wet and dry cases predict the same spectral changes. Thus, these results are thought to be representative of the dry cases even though they are not included in the analysis.

The accuracy of the magnitudes for GLLSM-predicted changes cannot be gauged by looking at the intuitive nature of the $\mathrm{C} / \mathrm{E}$ values; however, qualitatively the predicted changes seem to be in the right direction. 


\section{SUMMARY AND CONCLUSIONS}

The NIST fission reaction-rate measurements were described in Sect. 2. In the analysis of the NIST fission reaction rate measurements, it is important to explicitly specify the data used for the description of the driving ${ }^{252} \mathrm{Cf}$ spontaneous fission source, the description of the materials through which the neutrons traverse and the response fission foils. A comparison of MCNP results published previously with the current MCNP simulations, in Sect. 3, using the same NIST fission source representation and the same fission foil cross-section data, showed no appreciable differences between using the ENDF/B-V or ENDF/B-VI data for the neutron transport. However, the results are quite sensitive to the representation of the source fission spectrum.

For ${ }^{235} \mathrm{U}$, the water-moderated spheres underpredicted the fission rate by more than the bare sphere experiments. For ${ }^{238} \mathrm{U}$, the water-moderated spheres overpredicted the fission rate by more than the bare sphere experiments. The ENDF-based results were closer to the measured values by $3 \%$ than the LLNL-based results for ${ }^{238} \mathrm{U}$. The results for the bare-sphere experiments for ${ }^{237} \mathrm{~Np}$ indicate that the ENDF/B-V data were closest to the measurement, followed by the ENDF/B-VI data. The LLNL-based data for ${ }^{237} \mathrm{~Np}$ underestimated the fission rate for the bare-sphere experiments the most. All of the data libraries did a good job of calculating the water-moderated spheres for ${ }^{237} \mathrm{~Np}$. The bare-sphere experiments were underestimated by all the data libraries for ${ }^{239} \mathrm{Pu}(4$ to $5 \%)$, and the water-moderated sphere experiments were underestimated by a greater amount on average for ENDF-based and ENDL92 data. The LLNL dosimetry data only underestimated the fission rate an average of $3 \%$.

The "wet" measurements of the NIST water spheres were analyzed using the GLLSM procedures under various assumptions. The consistency analysis indicated that the ${ }^{238} \mathrm{U}$ and, to a much lesser extent, the ${ }^{235} \mathrm{U}$ calculated and measured data were inconsistent with each other. The least-squares approach did indeed narrow the deviation between the measured and calculated responses and decreased the uncertainties. A qualitative comparison of the least-squares-predicted cross-section changes vs the 
physical implication of the $\mathrm{C} / \mathrm{E}$ values indicates that the predicted changes are intuitively in the correct direction.

Future work will consider the inclusion of the "dry" measurements in the adjustment procedure of the NIST water spheres and a test of the effect of the incorporation of all the data into the criticality safety GLLSM package. Due to the findings of the sensitivity of the reported results to the source spectrum, further work is planned on a comparison of the NIST-values, the MCNP-Watt values, and the actual measured values. Additionally, a better estimate of uncertainties in the ${ }^{252} \mathrm{Cf}$ spectrum values will be pursued. 


\section{REFERENCES}

1. D. M. Gilliam and J. F. Briesmeister, "Neutron Leakage Benchmarks for Water Moderators," Reactor Dosimetry, ASTM STP 1228, Harry Farrar IV, E. Parvin Lippincott, and John G. Williams, Eds., American Society for Testing and Materials, Philadelphia, 1994.

2. D. M. Gilliam and J. F. Briesmeister, "Benchmark Measurements and Calculations of Neutron Leakage from Water Moderators," Chapter 9.1, p. 4-1 in Proceedings of the International Topical Meeting on Advances in Mathematics, Computations, and Reactor Physics, Pittsburgh, Pa, April 1991, American Nuclear Society, La Grange Park, IL,

3. D. M. Gilliam, V. Spiegel, C. M. Eisenhauer, E. Quang, J. F. Briesmeister, and J. S. Tang, “Neutron Leakage Benchmark for Criticality Safety Research,” Trans. Am. Nucl. Soc. 62, 340 (1990).

4. B. L. Broadhead, C. M. Hopper, R. L. Childs, and C. V. Parks, Sensitivity and Uncertainty Analyses Applied to Criticality Safety Validation, NUREG/CR-6655, Vol. 1 (ORNL/TM13692/V1), U.S. Nuclear Regulatory Commission, Oak Ridge National Laboratory, November 1999.

5. R. Kinsey, Data Formats and Procedures for the Evaluated Nuclear Data File, ENDF, BNLNCS-50496 (ENDF 102) 2 ${ }^{\text {nd }}$ Ed., (ENDF/B-V), Brookhaven National Laboratory, October 1979.

6. P. F. Rose, ENDF/B-VI Summary Documentation, BNL-NCS-17541 (ENDF-201) $4^{\text {th }}$ Ed., Brookhaven National Laboratory, October 1991.

7. R. J. Howerton, D. E. Cullen, R. C. Haight, M. H. MacGregor, S. T. Perkins, and E. F. Plechaty, The LLL Evaluated Nuclear Data Library (ENDL): Evaluation Techniques, Reaction Index, and Descriptions of Individual Reactions, UCRL-50400, Lawrence Livermore National Laboratory. 
8. J. S. Hendricks, S. C. Frankle, and J. D. Court, ENDF/B-VI Data for MCNP, LA-12891, Los Alamos National Laboratory, 1994.

9. J. A. Grundl and C. M. Eisenhauer, Compendium of Benchmark Neutron Fields for Reactor Dosimetry, NBS IR 85-3151.

10. See Appendix H of Reference 11.

11. J. F. Briesmeister, ed., MCNP - A General Monte Carlo Code for Neutron and Photon Transport, LA-7396-M, Rev. 2, Los Alamos National Laboratory, 1986.

12. M. E. Dunn, PUFF-III: A Code for Processing ENDF Uncertainty Data Into Multigroup Covariance Matrices, NUREG/CR-6650 (ORNL/TM-1999/235), U.S. Nuclear Regulatory Commission, Oak Ridge National Laboratory, June 2000.

13. R. L. Perel, J. J. Wagschal, and Y. Yeivin, “Analysis of Experimental Data: A General Review with Particular Reference to Monte Carlo Evaluation of Sensitivites," in Reactor Physics and Reactor Computations, U. Ronen and E. Elias eds., Ben-Gurion University of the Negev Press, Beer Sheva, Israel, 15-24, 1994.

14. D. M. Gilliam private communication to J. J. Wagschal, August 9, 1999. 


\section{INTERNAL DISTRIBUTION}

1. S. M. Bowman, 6011, MS-6370

2-6. B. L. Broadhead, 6011, MS-6370

7. W. C. Carter, 6011, MS-6370

8. R. L. Childs, 6011, MS-6370

9. M. E. Dunn, 6011, MS-6370

10. M. D. DeHart, 6011, MS-6370

11. K. R. Elam, 6011, MS-6370

12. M. B. Emmett, 6011, MS-6370

13. I. C. Gauld, 6011, MS-6370

14. S. Goluoglu, 6011, MS-6370

15. N. M. Greene, 6011, MS-6370

16. O. W. Hermann, 6011, MS-6370

17. D. F. Hollenbach, 6011, MS-6370

18-23. C. M. Hopper, 6011, MS-6370

24. M. A. Kuliasha, 6025, MS-6435

25. L. C. Leal, 6011, MS-6370

26. C. V. Parks, 6011, MS-6370
27. L. M. Petrie, 6011, MS-6370

28. R. T. Primm, 6025, MS-6363

29. C. E. Pugh, 9201-3, MS-8063

30. B. T. Rearden, 6011, MS-6370

31. R. W. Roussin, 6025, MS-6362

32. C. E. Sanders, 6011, MS-6370

33. C. H. Shappert, 4500 N, MS-6237

34. T. E. Valentine, 6025, MS-6362

35. J. C. Wagner, 6011, MS-6370

36. R. M. Westfall, 6011, MS-6370

37. Central Research Library, 4500N, MS-6191

38. ORNL Laboratory Records - RC 4500N, MS-6285

\section{EXTERNAL DISTRIBUTION}

39. F. M. Alcorn, BWX Technologies, Inc., Naval Nuclear Fuel, 212 Windsor Rd., Lynchburg, VA 24502

40. S. Almodovar, Fluor Daniel Hanford, P.O. Box 1000, Mail Stop A3-02, Richland, WA 99352-1000

41. S. Altschuler, U.S. Department of Energy, Richland Operations, 825 Jadwin, R3-79, Richland, WA 99352

42. R. E. Anderson, Los Alamos National Laboratory, P.O. Box 1663, NIS-6, MS J562, Los Alamos, NM 87545

43. W. L. Andrews, Defense Nuclear Facilities Safety Board, 625 Indiana Ave., Washington, DC 20004

44. C. Apperson, Westinghouse Savannah River Company, Savannah River Site, Bldg. 773-11A, Aiken, SC 29808-0001 
45. M. G. Bailey, NMSS/SFPO/SLID, U.S. Nuclear Regulatory Commission, MS O13-D13, Washington, DC 20555

46. G. H. Bidinger, Nuclear Criticality Safety, 17016 Cashell Road, Rockville, MD 20853

47. R. N. Blomquist, Argonne National Laboratory, RA/208, 9700 S. Case Ave., Argonne, IL 60439-4842

48. C. Boman, BWX Technologies, Inc., Naval Nuclear Fuel, P.O. Box 785, Lynchburg, VA 24505

49. M. C. Brady Raap, Duke Engineering Services, 10503 W. Williams Road, Benton City, WA 99320

50-54. J. F. Briesmeister, Los Alamos National Laboratory, Group X-Ci MS F663, P.O. Box 1663, Los Alamos, NM 87545

55. J. B. Briggs, INEEL, P.O. Box 1625, MS-3855, Idaho Falls, ID 83402

56. T. Burns, Defense Nuclear Facilities Safety Board, 625 Indiana Ave., Washington, DC 20004

57. R. D. Busch, University of New Mexico, Chemical and Nuclear Engineering Department, FEC 209, Albuquerque, NM 87131-1341

58. D. E. Cabrilla, U.S. DOE EM-66, Nuclear Material Stabilization, 19901 Germantown Road, Germantown, MD 20874-1290

59. D. E. Carlson, NMSS/SFPO/TRD, U.S. Nuclear Regulatory Commission, MS O13-D13, Washington, DC 20555

60. K. J. Carroll, Lockheed Martin Energy Systems, Y-12 Plant, P.O. Box 2009, Bldg. 9110 , MS-8238, Oak Ridge, TN 37831-8238

61. P. Cousinou, Institute of Protection and Nuclear Safety, B. P. 6 - 92265 Fontenay-AuxRoses, Cedex, France

62. D. E. Cullen, Lawrence Livermore National Laboratory, L-086, 7000 East Ave., Livermore, CA 94550-9234

63. D. R. Damon, NMSS/FCSS/FLIB, U.S. Nuclear Regulatory Commission, MS T8-A33, Washington, DC 20555

64. J. R. Davis, NMSS/FCSS, U.S. Nuclear Regulatory Commission, MS T8-A33, Washington, DC 20555

65. J. W. Davis, Framatome Cogema Fuels, CRWMS M\&O, 1261 Town Center Dr., Las Vegas, NV 89134

66. R. L. Dintaman, U.S. Department of Energy, DP-13, 19901 Germantown Rd., Germantown, MD 20874-1290

67. H. L. Dodds, University of Tennessee, Nuclear Engineering Dept., 214 Pasqua Engineering Bldg., Knoxville, TN 37922

68. T. W. Doering, Framatome Cogema Fuels, 1261 Town Center Drive, Las Vegas, NV 89124

69. F. Eltawila, RES/DSARE/SMSAB, U.S. Nuclear Regulatory Commission, MS T10-E32, Washington, DC 20555

70. J. D. Evans, U.S. Department of Energy, S-3.1/VISTA, 1000 Independence Ave., S.W., Washington, DC 22085 
71. H. D. Felsher, NMSS/FCSS/FLIB, U.S. Nuclear Regulatory Commission, MS T8-A33, Washington, DC 20555

72. P. Felsher, Rocky Flats Environment Technology Site, Bldg. T886B, P.O. Box 464, Golden, CO 80402-0464

73. J. R. Felty, Science Applications Int'l Corp., 2418 N. Dickerson St., Arlington, VA 22207

74. I. E. Fergus, U.S. Department of Energy, EH-22, 20300 Century Blvd., Germantown, MD 20874

75. P. Finck, Argonne National Laboratory, 9700 South Cass Avenue, RA/208, Argonne, IL 60439-4842

76-80. S. C. Frankle, Los Alamos National Laboratory, Group X-Ci MS F663, P.O. Box 1663, Los Alamos, NM 87545

81. E. K. Fujita, Argonne National Laboratory, 9700 South Cass Avenue, RA/208, Argonne, IL 60439-4842

82. A. S. Garcia, U.S. Department of Energy, Idaho Operations Office, 850 Energy Dr., MS 1154, Idaho Falls, ID 83401-1563

83. E. Greenspan, University of California, 4101 Etchevenny Hall, Berkeley, CA 94720

84. D. M. Grilliam, National Institute of Standards and Technology, 100 Bureau Drive, Gaiothersburg, MD 20899-8461

85. J. Gulliford, Winfrith Technology Centre, 306/A32, AEA Technology PLC, Winfrith, Dorchester, Dorset DT2 8DH

86. G. R. Handley, Lockheed Martin Energy Systems, P.O. Box 2009, 9110, MS-8238, Oak Ridge, TN 37831

87. D. K. Hays, Los Alamos National Laboratory, P.O. Box 1663, Los Alamos, NM 87545

88. D. Heinrichs, Lawrence Livermore National Laboratory, P.O. Box 808, MS L-128, Livermore, CA 94551

89. A. B. Hoffman, Lockheed Martin Idaho Tech. Co., P.O. Box 1625, MS 3458, Idaho Falls, ID 83415-3458

90. R. J. Howerton, Lawrence Livermore National Laboratory, L-059, 7000 East Ave., Livermore, CA 94550-9234

91. S. T. Huang, Lawrence Livermore National Laboratory, MS L-128, P.O. Box 808, Livermore, CA 94551

92. J. C. Ingram, Bechtel Jacobs Company LLC, P. O. Box 4699, Bldg. K-1320, MS-7592, Oak Ridge, TN 37831-7592

93. E. F. Kendall, U.S. Department of Energy, Oak Ridge Operations Office, YSO, P.O. Box 2001, Oak Ridge, TN 37831

94. K. D. Kimball, NISYS Corporation, 6055 Atlantic Blvd., Suite G-2, Norcross, GA 30071

95. R. P. Koopman, Lawrence Livermore National Lab., P.O. Box 808, L-467, Livermore, CA 94551

96. M. A. Lee, U.S. Department of Energy, Livermore Operations, 7000 East St., P.O. Box 808, L-293, Livermore, CA 94551-0808

97. R. Libby, Pacific Northwest National Laboratory, P.O. Box 999, M/S K7-74, Richland, WA 99352 
98. J. J. Lichtenwalter, Navarro Research and Engineering, P.O. Box 2009, Bldg. 9110, MS-8238, Oak Ridge, TN 37831-8238

99-103. R. C. Little, Los Alamos National Laboratory, Group X-Ci MS F663, P.O. Box 1663, Los Alamos, NM 87545

104. C. D. Manning, Siemens Power Corporation, 2101 Horn Rapids Road, P.O. Box 130, Richland, WA 99352-0130

105. R. McBroom, U.S. Department of Energy, Oak Ridge Operations Office, YSO, P.O. Box 2001, Oak Ridge, TN 37831

106. J. McKamy, U.S. Department of Energy, EH-34, 19901 Germantown Road, Germantown, MD 20874-1290

107. R. D. McKnight, Argonne National Laboratory, 9700 S. Cass Ave., Argonne, IL 604394842

108. T. P. McLaughlin, Los Alamos National Laboratory, P.O. Box 1663, Los Alamos, NM 87545

109. D. E.I. Mennerdal, E M Systems, Starvãgen 12, Täby, SWEDEN S-18357

110. R. D. Montgomery, Nuclear Fuel Services, Inc., 1205 Banner Hill Rd., Erwin, TN 37650

111. D. C. Morey, NMSS/FCSS/FCOB, U.S. Nuclear Regulatory Commission, MS T8-A33, Washington, DC 20555

112. L. Mantierth, GE Nuclear Energy, P.O. Box 780, Castle Hayne Road, Wilmington, NC 28402

113. J. A. Morman, Argonne National Laboratory, 9700 S. Cass Ave., Bldg. 208, C237B, Argonne, IL 60439-4842

114. R. D. Mosteller, Los Alamos National Laboratory, MS J562, Los Alamos, NM 87545

115. K. A. Niemer, Duke Engineering \& Services, 400 S. Tryon St., WC26B, P.O. Box 1004, Charlotte, NC 28201-1004

116. H. Okuno, Japan Atomic Energy Research Institute, 2-4 Shirakara-shirane, Tokai-mura, Ibaraki-ken, JAPAN 319-1195

117-118. Office of Scientific and Technical Information, U.S. Department of Energy, P.O. Box 62, Oak Ridge, TN 37831

119. S. A. Parra, Lawrence Livermore National Laboratory, P.O. Box 808, MS L-128, Livermore, CA 94551

120. L. E. Paulson, Manager, Nuclear Safety, GE Nuclear Energy, P.O. Box 780, Castle Hayne Road, Wilmington, NC 28405

121. S. Payne, U.S. DOE/AL/SASD, P.O. Box 5400, Albuquerque, NM 87185-5400

122. V. A. Perin, NMSS/DWM/HLWB, U.S. Nuclear Regulatory Commission, NMSS/DWM, MS T7-F3, Washington, DC 20555

123. J. Person, Lawrence Livermore National Laboratory, P.O. Box 808, MS L-128, Livermore, CA 94551

124. R. E. Pevey, University of Tennessee, Nuclear Engineering Dept., 214 Pasqua Engineering Bldg., Knoxville, TN 37922

125. J. Philbin, Sandia National Laboratory, P.O. Box 5800, Albuquerque, NM 87185-1143 
126. A. W. Prichard, Pacific Northwest National Laboratory, P.O. Box 999, MSIN: K8-34, Richland, WA 99352

127. M. Rahimi, NMSS/DWM/HLWB, U.S. Nuclear Regulatory Commission, MS T7-F3, Washington, DC 20555

128. T. A. Reilly, Westinghouse Safety Management Solutions, 1993 South Centennial Dr., Aiken, SC 29803

129. J. D. Roarty, Defense Nuclear Facilities Safety Board, 625 Indiana Ave., N.W., Suite 700, Washington, DC 2004

130. R. C. Robinson, Lockheed Martin Energy Systems, P.O. Box 2009, 9110, MS-8238, Oak Ridge, TN 37831

131. C. Rogers, Duke Engineering Services, 10503 W. Williams Road, Benton City, WA 99320

132. C. T. Rombough, CTR Technical Services, Inc., 950 Sugarloaf Rd., Manitou Springs, CO 80829

133. B. Rothleder, U.S. Department of Energy, EH-31, 19901 Germantown Rd., Germantown, MD 20874-1290

134. M. K. Sheaffer, Lawrence Livermore National Laboratory, P.O. Box 808, L-634, Livermore, CA 94550

135. G. L. Stimmell, Manager, General Electric Co., Vallecitos Nuclear Center, P.O. Box 460, Vallecitos Road, Pleasanton, CA 94566

136. J. T. Taylor, Principle Engineer - CSE, GE Nuclear Energy, P.O. Box 780, Castle Hayne Road, Wilmington, NC 28402

137. R. G. Taylor, Lockheed Martin Energy Systems, P.O. Box 2009, 9110, MS-8238 Oak Ridge, TN 37831

138. T. Taylor, Lockheed Martin Idaho Tech. Co., P.O. Box 1625, MS 3458, Idaho Falls, ID 83415-3458

139. D. A. Thomas, Framatome Cogema Fuels, 1261 Town Center Drive, Las Vegas, NV 89124

140. C. Tripp, NMSS/FCSS/FSPB, U.S. Nuclear Regulatory Commission, MS T8-A33, Washington, DC 20555

141. J. A. Thornton, Duke Engineering \& Services, 400 S. Tryon St., WC26B, P.O. Box 1004, Charlotte, NC 28201-1004

142. H. Toffer, Fluor Daniel Northwest, Inc., P.O. Box 1050, MSIN B4-44, 1100 Jadwin Ave., Richland, WA 99352-1050

143. E. F. Trumble, Westinghouse Safety Management Solutions, P.O. Box 5388, 1993 South Centennial Dr., Aiken, SC 29803

144-148. J. J. Wagschal, Racah Institute of Physics, The Hebrew University of Jerusalem, 91904, Jerusalem, ISRAEL

149. M. Wangler, Office of Site Operations, EM-70/CLV-1059, U.S. Department of Energy, 19901 Germantown Road, Germantown, MD 20874-1290

150. L. Wetzel, BWX Technologies, Inc., Naval Nuclear Fuel, P.O. Box 785, Lynchburg, VA 24505

151. S. A. Whaley, U.S. Nuclear Regulatory Commission, MS O6-G22, Washington, DC 20555 
152. B. H. White IV, U.S. Nuclear Regulatory Commission, MS O6-F18, Washington, DC 20555

153. D. W. Williams, Westinghouse Electric Corporation, 5801 Bluff Rd MS\#15, Columbia, SC 29209

154. Mark Williams, Louisiana State University, Baton Rouge, LA 70803-5820

155. R. E. Wilson, DOE Rocky Flats, 10808 Highway 93, Unit A, Golden, CO 80403

156. C. J. Withee, NMSS/SFPO/TRD, U.S. Nuclear Regulatory Commission, MS O13-D13, Washington, DC 20555 